\title{
Metamorphism and aqueous alteration in low petrographic type ordinary chondrites
}

\author{
Derek W. G. Sears ${ }^{1}$, Andrew D. Morse ${ }^{2}$, Robert Hutchison ${ }^{3}$, R. Kyle Guimon ${ }^{1,5}$, Lu Jie $^{1}$, C. M. O'D. Alexander 2,6 , \\ Paul H. Benoit ${ }^{1}$, Ian Wright ${ }^{2}$, Colin Pillinger ${ }^{2}$, Tian Xie ${ }^{4,7}$ and Michael E. Lipschut ${ }^{4}$ \\ 'Cosmochemistry Group, Department of Chemistry and Biochemistry, University of Arkansas, Fayetteville, Arkansas 72701, USA \\ ${ }^{2}$ Planetary Sciences Unit, Department of Earth Science, The Open University, Milton Keynes MK7 6АA. U. K. \\ ${ }^{3}$ Mineralogy Department, Natural History Museum, Cromwell Road, London SW7 5BD, U. K. \\ ${ }^{4}$ Department of Chemistry, Purdue University, West Lafayette, Indiana 47907, USA \\ SPresent address: Natural Science Division, Missouri Baptist University, St. Louis, Missouri 63142, USA \\ ${ }^{6}$ Present address: Department of Terrestrial Magnetism, 5241 Broad Branch Rd. NW, Washington, D. C. 20015, USA \\ ${ }^{7}$ Present address: IT Corporation, Oak Ridge, Tennessee 37830, USA \\ (Received 1994 January 19; accepted in revised form 1994 December 8)
}

\begin{abstract}
In order to investigate the relative importance of dry metamorphism and aqueous alteration in the history of chondrules, chondrules were hand-picked from the Semarkona (petrographic type 3.0), Bishunpur (3.1), Chainpur (3.4), Dhajala (3.8) and Allegan (5) chondrites, and matrix samples were extracted from the first three ordinary chondrites. The thermoluminescence (TL) properties of all the samples were measured, and appropriate subsets of the samples were analyzed by electron-microprobe and radiochemical ncutron activation and the water and $\mathrm{H}$-isotopic composition determined.

The TL data for chondrules from Semarkona and Bishunpur scatter widely showing no unambiguous trends, although group Bl chondrules tend to have lower sensitivities and lower peak temperatures compared with group A5 chondrules. It is argued that these data reflect the variety of processes accompanying chondrule formation. The chondrules show remarkably uniform contents of the highly labile elements, indicating mineralogical control on abundance and volatile loss from silicates and loss and recondensation of mobile chalcophiles and siderophiles in some cases. Very high $\mathrm{D} / \mathrm{H}$ values (up to $\sim 8000 \%$ SMOW) are observed in certain Semarkona chondrules, a confirmation of earlier work.

With increasing petrographic type, mean TL sensitivities of the chondrules increase, the spread of values within an individual meteorite decreases, and peak temperatures and peak widths show trends indicating that the TL is mainly produced by feldspar and that dry, thermal metamorphism is the dominant secondary process experienced by the chondrules. The TL sensitivities of matrix samples also increase with petrographic type. Chainpur matrix samples show the same spread of peak temperatures and peak widths as Chainpur chondrules, indicating metamorphism-related changes in the feldspar are responsible for the TL of the matrix. The TL data for the Semarkona and Bishunpur matrix samples provide, at best, only weak evidence for aqueous alteration, but the matrix contains $\mathrm{H}$ with approximately terrestrial $\mathrm{D} / \mathrm{H}$ values, cven though it contains much water. Secondary processes (probably aqueous alteration) presumably lowered the $\mathrm{D} / \mathrm{H}$ of the matrix and certain chondrules. While chondrule properties appear to be governed primarily by formation processes and subsequent metamorphism, the matrix of Scmarkona has a more complex history involving aqueous alteration as a meteorite-wide process.
\end{abstract}

\section{INTRODUCTION}

The chondrites provide much information on conditions and processes in the early Solar System and even on the interstellar medium (Kerridge and Matthews, 1988). However, there is uncertainty as to which properties reflect nebular processes (i.e., preaccretionary processes responsible for the "precursors") and which result from processes occurring on the parent body. Preaccretionary processes generally include mixing of different precursors, gas-solid reactions occurring during condensation in the nebula and during chondrule formation. Parent-body processes usually involve reactions between condensed phases, including liquids. The many and varied effects of dry metamorphism in ordinary chondrites have been well documented (e.g., McSween et al., 1988), but aqueous alteration effects have been observed in type 3 ordinary chondrites only recently (Hutchison et al., 1987). To complicate matters further, most chondrites are breccias, and since it may involve both devolatilization and recondensation, brecciation may sometimes result in effects normally associated with the nebula.
Figure 1 summarizes much of the present discussion concerning the metamorphic and aqueous alteration history of type 3 ordinary chondrites. Conventionally, it has been assumed that the type 3 ordinary chondrites represent a simple single metamorphic series extending from type 3.0 to type 6 . However, IIutchison et al. (1987) mentioned the possibility of type 3.0 being produced from higher types by aqueous alteration. Also, Guimon et al. (1988) found that while fairly severe laboratory heating treatments caused an increase in TL sensitivity and other changes associated with increasing petrographic type, consistent with the conversion of type 3.3 to type 6 by metamorphism, low-temperature hydrothermal treatments cause a decrease in TL sensitivity consistent with the conversion of type 3.3 to type 3.0 by aqueous alteration (Fig. 1b, after Sears and Dodd, 1988). Thus, the possibility exists that type 3 ordinary chondrites show some similarity to carbonaceous chondrites that McSween (1979) described in terms of the cartoon in Fig. la.

For the present study, we removed chondrules from four type 3 and one type 5 chondrite, and matrix samples from three type 3 ordinary chondrites and determined their induced TI, properties. 


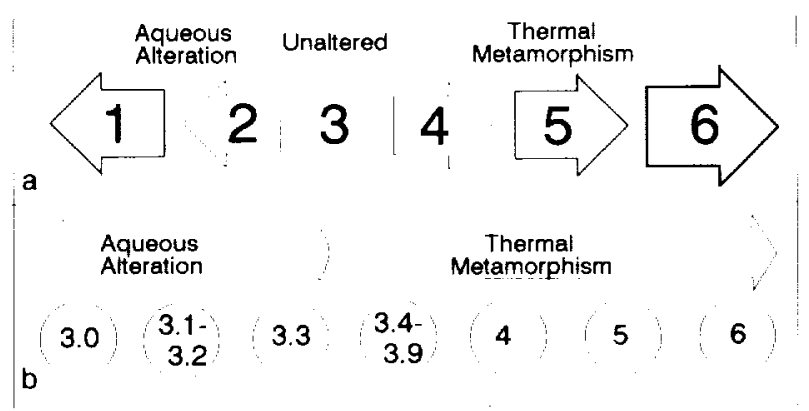

FIG. 1. A cartoon showing ideas concerning the relative importance of aqueous alteration and metamorphism in (a) carbonaceous chondrites (McSween, 1979) and (b) the type 3 ordinary chondrites (Sears and Dodd, 1988). The type 3 ordinary chondrite scenario is based on laboratory annealing experiments. These experiments demonstrate that although the series type 3.3 to type 6 appears to be the result of dry thermal metamorphism, it is possible that the type $\leq 3.3$ represent either metamorphism along the series 3.0 to 3.3 or aqueous alteration from 3.3 to 3.0 (Guimon et al., 1988). Petrographic observations suggest that Fig. $1 \mathrm{~b}$ might be an oversimplification in that some type 3.1 and 3.2 chondrites are unaffected by aqueous processes, while Tiechitz (type 3.4) may have experienced aqueous alteration.

Pieces of many of these samples were examined petrographically, and many of the chondrules from three of the type 3 chondrites were analyzed by radiochemical neutron activation analysis. Twenty-two chondrules and four matrix samples from Semarkona were also analyzed for water content and $\mathrm{H}$ isotopes. Preliminary discussions of various aspects of this work have been presented (Sears et al., 1988a,b; Morse et al., 1987, 1988; Morse, 1991). We conclude that although type 3.0 chondrules closely resemble their preaccretionary form and, thus, may be considered the most "primitive" of the chondrules in ordinary chondrites, the matrix suffered extensive aqueous alteration following accretion on the meteorite parent body. We also conclude that it is doubtful that any type 3 ordinary chondrite contains matrix that is entirely unaltered nebular dust.

\section{EXPERIMENTAL}

\section{Chondrule Sampling}

Chondrules and matrix fragments were hand-picked from Semarkona, Bishunpur, Chainpur, Dhajala and Allegan. A fragment of meteorite, $\sim 200 \mathrm{mg}$, was placed in a V-shaped, stainless steel plate and then gently crushed in a vise. The samples were selected under a low-powered binocular microscope using cleaned stainless steel dental tools. Chondrules were selected by their sphericity and coherence and matrix by its uniform very fine-grained dark appearance after crushing. Each sample was briefly described, and matrix adhering to chondrules was removed to the extent possible. Chondrules could not be extracted from Bishunpur in the way described above because they would fragment rather than separate cleanly from the unique glassy, and especially tough, matrix (Alexander et al., 1989b). Instead, we located chondrules on fracture faces and removed them by chiselling. Semarkona, Bishunpur and Chainpur chondrules were weighed on a Cahn balance, while the masses of the Dhajala and Allegan chondrules were calculated from their diameter assuming sphericity and a density of $3.3 \mathrm{~g} \mathrm{~cm}^{-1}$. Each sample was wrapped in thick aluminium foil and split into three parts by crushing with a dental mallet. The fragment that best sampled the chondrule core-to-rim was used to make a polished section. The largest remaining fragment was used for HI-isotope analysis, and the remainder was used for TL measurements. The TI. samples were then used for radiochemical neutron activation.

\section{Petrography and Mineral/Phase Analysis}

Each chondrule fragment was placed on the side of $-0.5-\mathrm{mm}$ oblique resinfilled hole in a plastic microscope slide. After tumbling to ensure good adhesion, the fragment was oriented so as produce the most representative section. With about six samples per slide, the chondrules were ground and polished in the normal way. Petrographic descriptions were recorded, backscattered electron images were prepared, and the phenocrysts and mesostasis were analyzed by electron-microprobe analysis. A summary of our data appears in Table 1; more details may be found in Morse (1991). Some chondrules were not classified because of the lack of analytical data. About $5 \%$ of the chondrules (usually small fragments) were lost in polishing, and some were not mounted for analysis for other reasons (too small, lost in handling, efc.).

\section{Thermoluminescence Measurements}

The TL apparatus and procedures and the cathodoluminescence (CL) imaging were described by Sears and Weeks (1983) and Sears et al. (1989). The natural TL was removed by heating the sample to $500^{\circ} \mathrm{C}$ in the TL apparatus and $\mathrm{TL}$ induced by a $250 \mathrm{mCi}{ }^{90} \mathrm{Sr} \beta$ source was measured. Bulk samples of the Dhajala chondrite were used for normalization and for daily and long-term stability check of the apparatus. Three to five measurements were made for each chondrule Tl chip. Averages and standard deviations were determined. On two occasions, the TL chip was large enough for further subdivision, and each subchip was measured three times. As with earlier work, we report the maximum intensity of the TL normalized to Dhajala (the TL sensitivity), the full-width at half-maximum of the major Tl, peak (or peak width) and the temperature of the maximum of the TL peak (peak temperature). Because chondrule masses ranged over three orders of magnitude, TL sensitivities were mass-normalized (Sears et al., 1984). Our TL data for Dhajala and Allegan chondrules were the subject of previous reports where details of the Dhajala data may be found (Sears et al., 1984; Keck et al., 1986; Guimon and Sears, 1987). Data for the remaining samples appear in Tables 2 and 3.

\section{Isotopic Analysis}

Hydrogen-isotope analysis was performed on 26 Semarkoma samples using a modified 602E SIRA mass spectrometer (Morse, 1991). The sample preparation and inlet system were maintained at $100^{\circ} \mathrm{C}$. Reference gas from a commercial cylinder $(\delta D \cdots 650 \%$ ) was loaded into the variable volume bellows at the beginning of cach day. The reference gas also facilitated the $\mathrm{H}_{3}{ }^{+}$ correction (Fisher and Brown, 1971).

Samples were placed in a quartz bucket, loaded into the furnace, and pyrolyzed in 45 -min steps. The gases released during each step $\left(\mathrm{I}_{2} \mathrm{O}\right)$, a little $\mathrm{CO}_{2}$ and $\mathrm{SO}_{2}$, and traces of $\mathrm{CH}_{4}$ and $\mathrm{H}_{2}$ ) were collected in a liquid-nitrogen cryotrap for $5 \mathrm{~min}$. All but the water were pumped away by heating to -110 ${ }^{\circ} \mathrm{C}$, and the water was then released by heating to $100^{\circ} \mathrm{C}$. After being collected in a stainless steel U-tube $\left(20 \mathrm{~cm} \times 1 / 16^{\prime \prime}\right.$ O.D. $\times 0.030^{\prime \prime}$ I.D.) at liquid nitrogen temperature, the water was reduced to $\mathrm{H}_{2}$ by passing through a $7 \mathrm{n}$ furnace consisting of $10 \mathrm{~cm}$ of $4 \mathrm{~mm} I . D$. quartz tube with the central $2 \mathrm{~cm}$ packed with $\mathrm{INO}_{3}$-cleaned $\mathrm{Zn}$ shot. From the $\mathrm{Zn}$ furnace, the $\mathrm{H}$ passed directly into the changeover valve of the mass spectrometer.

An estimate of the amount of water produced was made from the intensity of the mass 2 peak, $60 \mu \mathrm{g}$ of water giving a source pressure of about $4 \times 10^{-7}$ mbar and a major beam current of about $2 \times 10^{-9} \mu \mathrm{A}$ for $330 \mathrm{~min}$. A Cajon fitting with a septum allowed $60-\mu \mathrm{g}$ standard water samples to be injected with a $1-\mu L$ calibrated syringe.

The main problems encountered with this technique were a "memory effect" (i.e. incomplete removal of the water and $\mathrm{H}$ generated during previous measurements), a relatively large blank for the $\mathrm{Zn}$ furnace and fractionation of the sample gas $10 \%$ min. Careful control of the timing of injection, frequent use of SMOW samples, an empirical calibration and a blank correction were necessary. A variety of operating conditions and a $U$ furnace at $620^{\circ} \mathrm{C}$ did not remove the memory and blank problems. A summary of our data appears in Table 4. Details can be found in Morse (1991) and Morse et al. (1993).

\section{Chemical Analysis}

After TL measurement, volatile or otherwise mobile elements were determined in the chondrules separated from Semarkona, Bishunpur and Chainpur using the radiochemical neutron activation analysis methods described in Zolensky et al. (1992). The results appear in Table 5. Neutron activation analysis of samples previously used for $\mathrm{TL}$ measurements shows that the latter do not affect compositional data (our own unpublished work). The heating conditions necessary for devolatilization were experimentally determined by lkramuddin et al. (1977) and are considerably more severe than the momentary heating at $500^{\circ} \mathrm{C}$ required by the TL measurement.

\section{RESULTS}

\section{Petrographic Data and Chondrule Classification}

Table 1 lists textural descriptions, mesostasis $\mathrm{CaO}$ and $\mathrm{Na}_{2} \mathrm{O}$, olivine $\mathrm{FeO}$ and $\mathrm{CaO}$ and low-Ca pyroxene $\mathrm{FeO}$ and $\mathrm{CaO}$ where olivine was totally absent from the chondrule. The textural types described by Gooding and Keil (1981) are present in approximately the proportions they observed, except that because of the method 
TABLE 1. Petrographic and electron-microprobe data for some of the chondrules from type 3 ordinary chondrites in the present study, ${ }^{*+}$

\begin{tabular}{|c|c|c|c|c|c|c|c|c|c|c|c|c|c|}
\hline \multirow[b]{2}{*}{ \# } & \multirow[b]{2}{*}{ group } & \multirow[b]{2}{*}{$\mathrm{txt}$} & \multicolumn{2}{|c|}{$\mathrm{Ol} / \mathrm{Px}$} & \multicolumn{2}{|c|}{ Mesostasis } & \multirow[b]{2}{*}{$\#$} & \multirow[b]{2}{*}{ group } & \multirow[b]{2}{*}{ txt } & \multicolumn{2}{|c|}{$\mathrm{Ol} / \mathrm{Px}$} & \multicolumn{2}{|c|}{ Mesostasis } \\
\hline & & & $\mathrm{Fa} / \mathrm{Fs}$ & $\mathrm{CaO}$ & $\mathrm{Na}_{2} \mathrm{O}$ & $\mathrm{CaO}$ & & & & $\mathrm{Fa} / \mathrm{Fs}$ & $\mathrm{CaO}$ & $\mathrm{Na}_{2} \mathrm{O}$ & $\mathrm{CaO}$ \\
\hline \multicolumn{7}{|c|}{ Semarkona Chondrules } & \multicolumn{7}{|c|}{ Bishunpur Chondrules } \\
\hline 1 & $\mathrm{~B} 1$ & $\mathrm{PO}$ & 20 & 0.21 & 1.6 & 4.4 & 2 & $\mathrm{~B} 1$ & $\mathrm{P} / \mathrm{O}$ & 40 & --- & 1.5 & 2.0 \\
\hline 2 & B1 & $\mathrm{PP}$ & 12 & 0.11 & 1.4 & 2.3 & 3 & $\mathrm{Bl}$ & $\mathrm{G} / \mathrm{IC}$ & 28 & --- & 0.50 & 1.4 \\
\hline 6 & $\mathrm{~B} 1$ & $\mathrm{PO}$ & 9 & 0.13 & 1.6 & 1.3 & 4 & $\mathrm{~B} 1$ & BP & 10 & $\ldots$ & 2.1 & 2.3 \\
\hline 9 & --- & $\mathrm{RP}$ & 19 & -- & -- & --- & 5 & Al-4 & $\mu \mathrm{C} / \mathrm{P}$ & 1.5 & $\cdots$ & 0.76 & 4.3 \\
\hline 11 & $\mathrm{~B} 1$ & $\mathrm{PO}$ & 16 & 0.11 & 0.65 & 7.6 & 7 & & GP & 30 & --- & --- & -- \\
\hline 14 & $\mathrm{~B} 1$ & PO & 8 & 0.12 & 0.71 & 6.1 & 8 & $\mathrm{~B} 1$ & $\mathrm{BO} / \mathrm{P}$ & 30 & --- & 3.7 & 2.5 \\
\hline 17 & $\mathrm{~A} 1$ & --- & 1.5 & --- & 0.46 & 14.3 & 10 & $\mathrm{~B} 1$ & $\mathrm{P} / \mathrm{BP}$ & 14 & 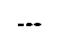 & 2.0 & 3.3 \\
\hline 19 & Al & POP & 1.5 & 0.25 & 0.4 & 14.3 & 12 & $\mathrm{~B} 1$ & $\mathrm{RP}$ & 13 & ..- & 3.2 & 0.89 \\
\hline 20 & B1 & $\mathrm{PP}$ & --- & --- & 1.3 & 2.3 & 13 & $\mathrm{Bl}$ & $\mathrm{PP}$ & 33 & -.- & 1.9 & 2.1 \\
\hline 22 & $\mathrm{~B} 1$ & $\mathrm{PO}$ & 10 & 0.15 & 1.8 & 1.6 & 15 & & $\mathrm{P} / \mathrm{O}$ & 28 & --- & --- & --- \\
\hline 23 & $A 2$ & $\mathrm{POP}$ & 8 & 0.13 & 1.2 & 6.2 & 18 & $\mathrm{Bl}$ & $\mathrm{RP}$ & 30 & -.. & 2.3 & 1.5 \\
\hline 26 & $B 1$ & $\mathrm{PP}$ & 14 & -.- & 2.3 & 2.9 & 19 & -- & $\mathrm{RP}$ & 33 & --- & --- & --- \\
\hline 28 & $\mathrm{~B} 2$ & --- & -.. & $\ldots$ & 4.0 & 3.5 & 20 & $\mathrm{~A} 2$ & RP & 20 & -.. & 1.3 & 2.0 \\
\hline 29 & $\mathrm{~B} 1$ & $--\cdot$ & 16 & --- & 3.1 & 7.4 & 21 & $\mathrm{~B} 1$ & GOP & 8 & -.- & 2.2 & 3.4 \\
\hline 33 & $B 1$ & C & 33 & --- & 0.26 & 1.1 & 22 & A5 & POP & 3 & $<.05$ & ... & $\cdots$ \\
\hline 35 & --- & $\mathrm{C} / \mathrm{RP}^{\mathrm{P}}$ & 30 & $\ldots$ & 0.31 & 0.72 & 23 & & $\mathrm{RP}$ & $3 !$ & --- & 1.0 & 0.78 \\
\hline 36 & $B 1$ & POP & 13 & 0.05 & 1.8 & 3.4 & 25 & $\mathrm{~A} 3$ & $\mathrm{BO}$ & 0.5 & 0.33 & 6.8 & 11.1 \\
\hline 37 & $A 4$ & 0 & 17 & 0.29 & --- & -- & 26 & & $\mathrm{RP}$ & 28 & ... & 4.1 & 1.1 \\
\hline 39 & A5 & $\mathrm{PP}$ & 11 & --- & 6.8 & 4.4 & 27 & $\mathrm{~B} 1,2$ & $\mu \mathrm{CP}$ & 30 & --- & -- & --- \\
\hline 40 & A5 & POP & 11 & 0.28 & 7.2 & 4.1 & 28 & $\mathrm{~A} 2$ & POP & 2 & 0.23 & 7.3 & 10.1 \\
\hline 41 & 131 & POP & 10 & 0.07 & 1.7 & 0.67 & 29 & $\mathrm{~A} 1$ & PP & 0.5 & -- & 2.6 & 10.5 \\
\hline 42 & $\mathrm{BI}$ & $\mathrm{PO}$ & 18 & 0.23 & 1.7 & 0.35 & 30 & $\mathrm{~B} 1,2$ & POP? & 23.5 & 0.17 & --- & -- \\
\hline 44 & --- & C & 27 & --- & 0.37 & 2.0 & \multirow{2}{*}{\multicolumn{7}{|c|}{ Chainpur Chondrules }} \\
\hline 45 & $\cdots$ & $\mathrm{C} / \mathrm{RP}$ & 27 & --- & 0.33 & 1.6 & & & & & & & \\
\hline 46 & --- & $\mathrm{C} / \mathrm{RP}$ & 27 & --- & 0.28 & 1.1 & 20 & $B 1$ & PO & 19 & 0.13 & 3.2 & 4.1 \\
\hline 47 & $A 1-4$ & $\mathrm{PP}$ & 3 & --- & 4.9 & 7.6 & 21 & A5 & $\mathrm{PP}$ & 3 & $<.05$ & 5.2 & 9.8 \\
\hline 49 & $A 1-4$ & POP & 7 & $\ldots$ & --- & --- & 23 & --- & $\mathrm{RP}$ & 35 & 0.05 & --- & -- \\
\hline 50 & & I & 8.7 & --- & 0.31 & 13.4 & 24 & $\mathrm{~B} 1$ & POP & 15 & 0.09 & 2.7 & 3.1 \\
\hline 51 & A5 & I & $<.05$ & --- & 0.05 & 18.4 & 26 & $\mathrm{~B} 1$ & POIK & 6 & 0.12 & 2.8 & 1.9 \\
\hline 52 & B1 & PP & 15 &.-- & 0.79 & 2.3 & 41 & $\mathrm{Bl}$ & $\mu \mathrm{C}$ & 33 & 3.6 & 4.3 & 2.8 \\
\hline 53 & $\mathrm{~B} 1$ & PP & 24 &.-- & 0.47 & 1.9 & 42 & $\mathrm{~B} 1,2$ & $\mu \mathrm{C} / \mathrm{C}$ & 33 & 1.5 & $\cdots$ & ... \\
\hline 54 & $\mathrm{~B} 1$ & $\mathrm{PP}$ & 25 & --- & 0.63 & 3.0 & 43 & B1 & POP & 29 & 0.12 & 4.9 & 1.6 \\
\hline 55 & $\mathrm{~A} 3$ & POP & 7 & 0.29 & 1.2 & 6.2 & 44 & $\mathrm{~B} 1$ & $\mathrm{BP}$ & 35 & 0.19 & 4.2 & 0.96 \\
\hline 58 & $\mathrm{Al}$ & $\mathrm{POP}$ & 2 & 0.17 & --- & --- & 45 & A5 & $\mathrm{Cl}$ & 9.0 & 0.14 & 6.7 & 7.3 \\
\hline 59 & Al & $\mathrm{POP}$ & 2 & 0.16 & $<0.05$ & 14.6 & 46 & B2 & $\mathrm{RP}$ & 32 & 0.11 & 2.1 & 1.3 \\
\hline 60 & $B 1$ & $\mathrm{PO}$ & 22 & 0.40 & 0.69 & 1.2 & 52 & A5 & PP & 2 & 0.19 & 10.8 & 1.3 \\
\hline 64 & $\mathrm{~A} 3$ & POP & 2.2 & 0.12 & 1.2 & 6.9 & 54 & A5 & $\mathrm{RP}$ & 16 & 1.1 & 3.2 & 3.1 \\
\hline 65 & $B 1$ & $\mathrm{PP}$ & 25 & --- & 2.6 & 0.39 & 57 & A5 & $\mu \mathrm{CP}$ & 27 & 0.12 & 7.4 & 4.3 \\
\hline 66 & $B 1$ & PP & 8 & 0.40 & 1.8 & 4.0 & 58 & .. & $\mu \mathrm{CP}$ & 25 & 2.5 & $\ldots$ & --- \\
\hline 67 & $\mathrm{~B} 2$ & $\mathrm{PP}$ & 5 & --- & 4.7 & 1.5 & 59 & $\mathrm{~A}$ & GOP & 7 & 0.08 & --- & --. \\
\hline 68 & AS & $\mathrm{pP}$ & 23 & $\cdots$ & 11.4 & 0.86 & 60 & B1 & POP & 15 & 0.17 & 5.7 & 0.07 \\
\hline 69 & A4 & POP & 21 & 0.23 & 0.30 & 10.4 & 61 & $\mathrm{~B} 1$ & $\mathrm{PO}$ & 8 & 0.08 & 3.2 & 3.2 \\
\hline 70 & B1 & POP & 7 & 0.13 & 5.2 & 4.5 & 63 & B1 & POP & 7 & 0.07 & 8.0 & 0.68 \\
\hline 71 & Al-4 & $\mathrm{pP}$ & 2.5 & -- & 3.4 & 10.8 & 65 & $\mathrm{~A} 3$ & POP & 3 & 0.35 & 2.4 & 5.6 \\
\hline 72 & $\mathrm{~B} 1$ & POP & 20 & 0.18 & 2.5 & 5.8 & \multirow{2}{*}{\multicolumn{7}{|c|}{ Allegan Chondrules }} \\
\hline & rkona $\mathrm{M}$ & trix Sar & ples & & & & & & & & & & \\
\hline 4 & .- & IC & ...- & ... & .-- & ..- & 16 & A5 & $\cdots$ & 17 & 0.73 & 7.9 & 5.1 \\
\hline 16 & -- & IC & --- & $\ldots$ & $\ldots$ & $\ldots$ & $\begin{array}{l}33 \\
38\end{array}$ & $\begin{array}{l}\text { A5 } \\
\text { A5 }\end{array}$ & $\cdots$ & $\begin{array}{l}18 \\
19\end{array}$ & $\begin{array}{l}0.05 \\
0.03\end{array}$ & $\begin{array}{l}7.2 \\
6.3\end{array}$ & $\begin{array}{l}3.2 \\
6.7\end{array}$ \\
\hline 18 & -- & IC & --- & --- & --- & --- & 43 & A5 & --- & 12 & 0.05 & 7.2 & 16.9 \\
\hline 40 & -- & $\mathrm{R}$ & $\cdots$ & $\cdots$ & -- & -- & 46 & A5 & --- & 18 & 0.08 & 2.3 & 3.2 \\
\hline
\end{tabular}

* Group compositional groups according to Sears et al. (1992); $\mathbf{t x t}=$ textural descriptions according to Gooding and Keil (1981) with the following additions; $\mathrm{P}=$ pyroxene; $\mu \mathrm{C}$ - microcrystalline; $\mathrm{P} / \mathrm{O}=$ pyroxene-olivine intergrowths; $\mathrm{POIK}=$ poikylitic; $\mathrm{Cl}$, noritic clast; $\mathrm{BP}=$ barred pyroxene; $\mathrm{I}$ - other igneous textures; $\mathrm{O}=$ other; $\mathrm{GP}=$ granular pyroxene. The query by Bishunpur chondrule 30 indicates texture uncertain due to poor polish The matrix samples are described as "inter-chondrule"(IC) and "rim" (R). Fa refers to olivine phenocryst composition unless in italics in which case the value refers to $\mathrm{Fs} ; \mathrm{Na}_{2} \mathrm{O}$ and $\mathrm{CaO}$ refer to mesostasis compositions or whole chondrule analyses in the case of cryptocrystalline textures. Typically 4 - 5 olivine grains and $2-3$ mesostasis regions were analyzed for each chondrule.

+ Petrographic data for the Ihajala chondrules discussed here were presented in Sears et al. (1984). Most Dhajala chondrules are groups A5, A4 and B3. Very limited data were also obtained for the Allegan meteorite whose chondrules are equilibrated and members of group A5. 
used to extract chondrules from Bishunpur, pyroxene-rich chondrules were over represented. To a good approximation, the trends observed in our earlier studies (Dellart et al., 1992; Sears et $a l ., 1992)$ are also observed here. Olivine and mesostasis data are plotted in Fig. 2. Semarkona mesostasis compositions are spread over the normative quartz-albite-anorthite triangle and chondrule olivines contain $>0.1 \mathrm{wt} \% \mathrm{CaO}$. With increasing petrographic type, olivines lose $\mathrm{CaO}$ and their $\mathrm{FeO}$ approaches the value observed in equilibrated chondrites, while the chondrule mesostasis compositions migrate towards oligoclase compositions.

Figure 2 enables the present chondrules to be assigned to the compositional groups of Sears et al. (1992), which are also given in Table 1. Semarkona and Bishunpur mainly contain chondrules of groups A1, A2, A5 and B1, while our Chainpur chondrules are predominantly groups $B 1$ and $A 5$. All the chondrules separated from the Allegan chondrite are compositional group $\Lambda 5$. The

TABLE 2. Induced thermoluminescence data for chondrules separated from type 3 and the Allegan ordinary chondrites. ${ }^{*}$

\begin{tabular}{|c|c|c|c|c|c|c|c|c|c|c|c|c|c|c|}
\hline$\#$ & $\begin{array}{l}\text { Mass } \\
(\mathrm{mg})\end{array}$ & $\begin{array}{l}\text { TL sens. } \\
(\text { Dhaj }=1)\end{array}$ & $\begin{array}{r}\text { Temp } \\
\left({ }^{\circ} \mathrm{C}\right)\end{array}$ & $\begin{array}{l}\text { Width } \\
\left({ }^{\circ} \mathrm{C}\right)\end{array}$ & $\#$ & $\begin{array}{l}\text { Mass } \\
(\mathrm{mg})\end{array}$ & $\begin{array}{l}\text { TL sens. } \\
(\text { Dhaj = 1) }\end{array}$ & $\begin{array}{r}\text { Temp } \\
\left({ }^{\circ} \mathrm{C}\right)\end{array}$ & $\begin{array}{l}\text { Width } \\
\left({ }^{\circ} \mathrm{C}\right)\end{array}$ & $\#$ & $\begin{array}{l}\text { Mass } \\
(\mathrm{mg})\end{array}$ & $\begin{array}{l}\text { TL sens. } \\
\text { (Dhaj }=1 \text { ) }\end{array}$ & $\begin{array}{r}\text { Temp } \\
\left({ }^{\circ} \mathrm{C}\right)\end{array}$ & $\begin{array}{c}\text { Width } \\
\left({ }^{\circ} \mathrm{C}\right)\end{array}$ \\
\hline \multicolumn{2}{|c|}{ Semarkona } & & & & 9 & 0.213 & 0.00736 & 188 & $\cdots$ & 65 & 0.115 & 0.151 & 111 & 33 \\
\hline 1 & 1.18 & 0.000443 & $\cdots$ & $\cdots$ & 10 & 0.34 & 0.000077 & -- & $\ldots$ & & & & & \\
\hline 2 & 0.424 & 0.00123 & 130 & 50 & 11 & 0.0334 & 0.00547 & 126 & 40 & \multicolumn{2}{|c|}{ Allegan } & & & \\
\hline 6 & 0.335 & 0.000008 & -- & -- & 12 & 2.41 & 0.000543 & 180 & 146 & 1 & 0.75 & 1.66 & 184 & 145 \\
\hline 9 & 0.0758 & 0.03296 & 163 & 88 & & & 0.00391 & 180 & 131 & 2 & 0.65 & 0.00407 & -- & $\cdots$ \\
\hline 11 & 0.0689 & 0.000038 & $\cdots$ & -- & 15 & 0.106 & 0.000246 & -- & -.- & 3 & 0.06 & 0.301 & 185 & 149 \\
\hline 15 & 0.42 & 0.000621 & -- & --- & 18 & 0.723 & 0.00253 & 136 & 75 & 4 & 0.25 & 0.815 & 183 & 143 \\
\hline 17 & 0.0802 & 0.0586 & 142 & 92 & 19 & 1.07 & 0.000491 & 144 & 90 & 5 & 0.005 & 0.0815 & 186 & 124 \\
\hline 20 & 2.95 & 0.00023 & 179 & 93 & & & 0.000025 & --- & --- & 6 & 0.15 & 1.51 & 186 & 141 \\
\hline 22 & 0.0386 & 0.0271 & 186 & -- & 20 & 0.451 & 0.000058 & -- & -- & 7 & 2.18 & 11.9 & 196 & 148 \\
\hline 23 & 0.25 & 0.00377 & -.. & -- & 21 & 0.0546 & 0.00335 & 114 & 30 & 8 & 0.32 & 1.36 & 183 & 144 \\
\hline 26 & 0.0784 & 0.000033 & --- & $\cdots$ & 22 & 0.0149 & 0.00175 & -- & -- & 9 & 0.46 & 3.58 & 178 & 148 \\
\hline 28 & 0.109 & 0.000024 & $\cdots$ & - & 23 & 0.513 & 0.000051 & --- & $\ldots$ & 10 & 0.51 & 6.27 & 183 & 146 \\
\hline 29 & 0.46 & 0.00102 & --- & --- & 24 & 0.423 & 0.00166 & 170 & 115 & 11 & 0.10 & 1.38 & 187 & 146 \\
\hline 33 & 0.0872 & 0.003 & 175 & 160 & 25 & 0.0506 & 0.000516 & -- & -- & 12 & 0.47 & 0.943 & 183 & 143 \\
\hline 34 & 0.0915 & 0.016 & 103 & 84 & 26 & 0.664 & 0.000512 & 124 & 50 & 13 & 0.78 & 4.40 & 184 & 143 \\
\hline 36 & 0.226 & 0.00927 & 112 & 45 & 27 & 0.322 & 0.000081 & -- & -- & 15 & 0.13 & 0.684 & 182 & 149 \\
\hline \multirow[t]{2}{*}{39} & 0.673 & 0.0513 & 186 & 71 & 29 & 0.14 & 0.00502 & 142 & 75 & 16 & 0.1 & 0.464 & 184 & 141 \\
\hline & & 0.00485 & 189 & 116 & 30 & 0.702 & 0.00744 & 175 & 130 & 19 & 0.24 & 32.1 & 185 & 145 \\
\hline 40 & 0.324 & 0.00367 & 179 & 125 & 31 & 0.089 & 0.000294 & -- &.- & 20 & 0.39 & 2.64 & 187 & 146 \\
\hline 42 & 0.392 & 0.000007 & -- & -- & & & & & & 21 & 3.61 & 21.1 & 189 & 152 \\
\hline 44 & 0.4372 & 0.000470 & --- & -- & \multicolumn{2}{|c|}{ Chainpur } & & & & 22 & 0.75 & 2.68 & 182 & 139 \\
\hline 45 & 0.39 & 0.00482 & 155 & 125 & 1 & 170 & 2.51 & 104 & 63 & 23 & 0.1 & 1.00 & 185 & 145 \\
\hline 46 & 0.433 & 0.232 & 200 & 198 & 2 & 0.324 & 1.57 & 119 & 77 & 24 & 0.18 & 0.688 & 184 & 148 \\
\hline 47 & 0.0376 & 0.00583 & 185 & 165 & 3 & 1.15 & 0.0108 & 215 & 181 & 25 & 2.17 & 7.89 & 197 & 150 \\
\hline 50 & 0.0342 & 0.0214 & 145 & 113 & 4 & 3.24 & 0.00641 & 123 & 94 & 26 & 4.93 & 25.7 & 203 & 153 \\
\hline 51 & 0.251 & 0.0025 & 155 & 145 & 5 & 1.83 & 0.0262 & 133 & 112 & 27 & 1.06 & 9.44 & 190 & 148 \\
\hline 53 & 1.67 & 0.000907 & 156 & 90 & 6 & 0.446 & 0.904 & 118 & 73 & 28 & 0.39 & 2.32 & 189 & 147 \\
\hline 54 & 1.98 & 0.00145 & 158 & 100 & 11 & 2.99 & 0.00996 & 116 & 74 & 29 & 0.29 & 1.69 & 194 & 149 \\
\hline 55 & 0.472 & 0.000886 & 146 & 103 & 12 & 2.25 & 0.00227 & 132 & 136 & 30 & 0.21 & 0.790 & 181 & 149 \\
\hline 58 & 0.779 & 0.000782 & 149 & 120 & 15 & 0.0195 & 0.121 & 119 & 100 & 31 & 0.91 & 8.90 & 190 & 147 \\
\hline \multirow[t]{3}{*}{59} & 1.66 & 0.000583 & 181 & 150 & 16 & 0.891 & 0.00171 & 116 & 75 & 32 & 0.26 & 2.14 & 182 & 144 \\
\hline & 0.95 & 0.132 & 106 & -- & 18 & 0.126 & 0.0228 & 127 & 95 & 33 & 0.26 & 2.93 & 173 & 144 \\
\hline & 0.95 & 0.00055 & 139 & $\ldots$ & 20 & 0.333 & 0.00283 & 129 & 97 & 34 & 0.91 & 8.90 & 200 & 150 \\
\hline 60 & 0.0913 & 0.000429 & 120 & 55 & 21 & 0.407 & 0.855 & 127 & 74 & 36 & 0.22 & 2.25 & 180 & 143 \\
\hline 65 & 1.12 & 0.00117 & -- & -- & 44 & 4.42 & 0.00098 & 167 & 139 & 37 & 1.13 & 17.4 & 191 & 151 \\
\hline 66 & 0.444 & 0.000006 & --- & --- & 45 & 1.86 & 0.00189 & 117 & 75 & 38 & 0.59 & 6.44 & 198 & 146 \\
\hline 67 & 0.609 & 0.00193 & 158 & 120 & 48 & 4.98 & 0.00255 & 128 & 100 & 39 & 0.19 & 0.262 & 180 & 141 \\
\hline 68 & 0.325 & 0.00602 & 203 & 135 & 49 & 1.07 & 0.00219 & 138 & 110 & 40 & 0.26 & 1.48 & 183 & 146 \\
\hline 69 & 1.31 & 0.000399 & 140 & 110 & 51 & 3.82 & 0.00143 & 123 & 79 & 41 & 0.32 & 4.45 & 187 & 147 \\
\hline 70 & 0.296 & 0.115 & 187 & 142 & 52 & 0.769 & 0.00918 & 114 & 73 & 42 & 0.51 & 2.88 & 190 & 148 \\
\hline 71 & 0.0914 & 0.000028 & $\ldots$ & -- & 54 & 0.662 & 0.00237 & 120 & 100 & 43 & 0.31 & 1.81 & 183 & 147 \\
\hline \multirow[t]{2}{*}{72} & 1.64 & 0.000159 & 150 & 100 & 55 & 0.767 & 0.0133 & 125 & 118 & 44 & 0.39 & 1.81 & 179 & 145 \\
\hline & & & & & 56 & 0.049 & 0.0162 & 118 & 63 & 45 & 0.17 & 2.00 & 187 & 148 \\
\hline \multicolumn{2}{|c|}{ Bishunpur } & & & & 57 & 0.19 & 0.194 & 124 & 77 & 46 & 0.68 & 8.40 & 187 & 147 \\
\hline 2 & 0.793 & 0.00033 & --- & -- & 58 & 0.19 & 0.194 & 108 & 61 & 47 & 0.22 & 0.593 & 187 & 142 \\
\hline 3 & 1.01 & 0.000441 & 201 & 127 & 59 & 0.055 & 0.901 & 130 & 70 & 48 & 0.43 & 2.94 & 187 & 147 \\
\hline 4 & 0.183 & 0.000143 & --- & -- & 61 & 0.525 & 0.00149 & 110 & 70 & 49 & 0.11 & 0.945 & 183 & 145 \\
\hline 5 & 0.0394 & 0.000663 & -- & $\cdots$ & 62 & 0.244 & 0.711 & 104 & 60 & 50 & 0.09 & 0.942 & 181 & 148 \\
\hline 7 & 0.2809 & 0.00154 & 158 & 85 & 63 & 0.039 & 0.0261 & 155 & 100 & & & & & \\
\hline 8 & 0.268 & 0.000098 & $\ldots$ & -- & 64 & 3.42 & 0.214 & 105 & 62 & & & & & \\
\hline
\end{tabular}

\footnotetext{
* The $2 \sigma$ uncertainties are typically \pm 5 in the last figure. Data for Dhajala can be found in Sears et al. (1984).
} 

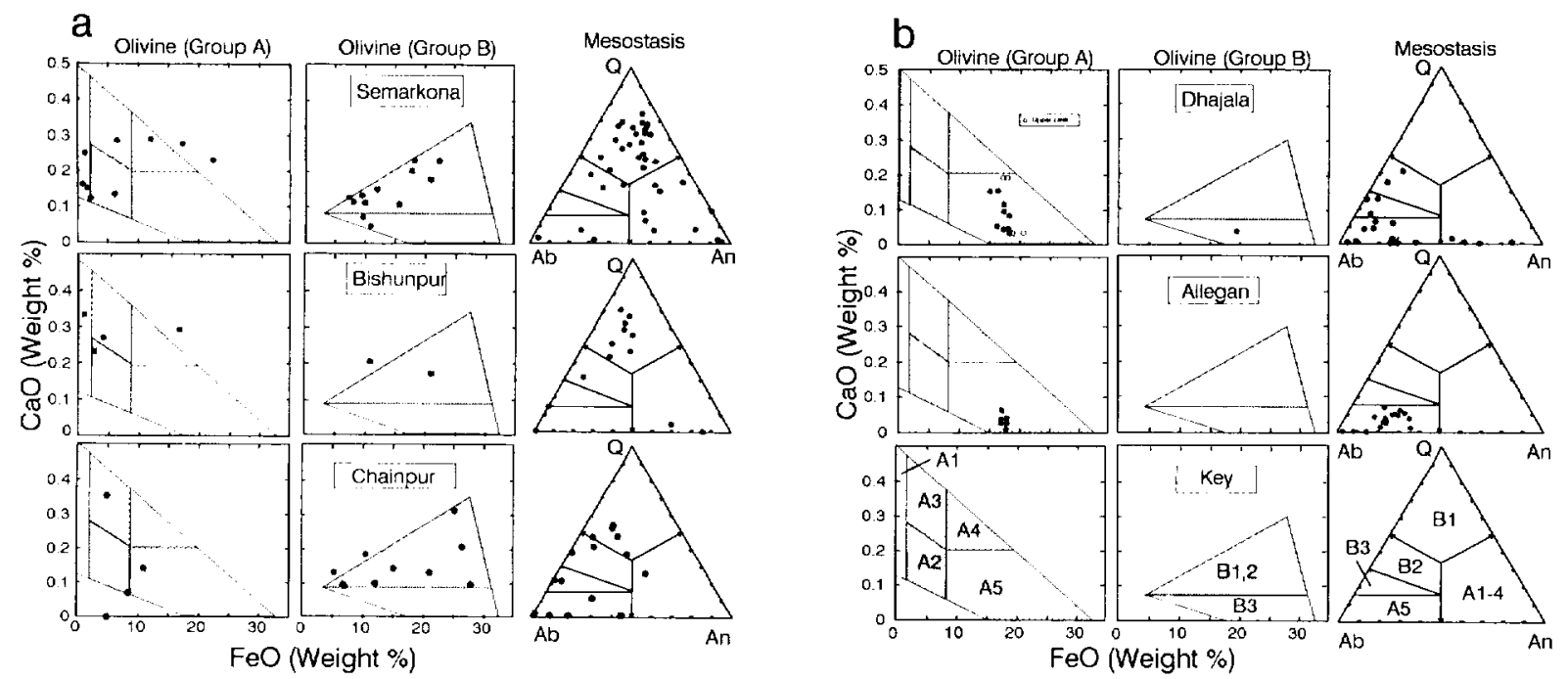

FIG. 2. Plots of the $\mathrm{CaO} v \mathrm{~s}$. $\mathrm{FeC}$ contents of chondrule olivines and of the mesostasis compositions (in terms of normative quartz, albite and anorthite) for chondrules from (a) Semarkona, Bishunpur and Chainpur and (b) Dhajala and Allegan. A key to the plots appears in Fig. 2b (after Sears et al., 1992, slightly simplified). The data enable the present chondrules to be assigned to the compositional classes given in Table 1 .

TAI3..5 3. Induced TL data for matrix samples from type 3 ordinary chondrites. ${ }^{*}$

\begin{tabular}{|c|c|c|c|c|}
\hline$\#$ & $\begin{array}{l}\text { Mass } \\
\text { (mg) }\end{array}$ & $\begin{array}{l}\text { Tl, sens. } \\
\text { (1)haj 1) }\end{array}$ & $\begin{array}{l}\text { Temp } \\
\left({ }^{\circ} \mathrm{C}\right)\end{array}$ & $\begin{array}{l}\text { Width } \\
\left({ }^{\circ} \mathrm{C}\right)\end{array}$ \\
\hline \multicolumn{5}{|c|}{ Semarkona } \\
\hline 4 & 0.783 & 0.000942 & --- & -- \\
\hline 13 & 0.362 & 0.00278 & 200 & 100 \\
\hline 16 & 0.846 & 0.00235 & 181 & 150 \\
\hline 18 & 0.287 & 0.000124 & 145 & 75 \\
\hline 25 & 0.186 & 0.00143 & 105 & 60 \\
\hline 31 & 0.190 & 0.000013 & --- & -- \\
\hline 38 & 0.0703 & 0.000526 & 169 & 125 \\
\hline 40 & 0.272 & 0.000474 & 146 & 140 \\
\hline 43 & 0.880 & 0.00042 & 175 & 115 \\
\hline 61 & --- & --- & 117 & 40 \\
\hline \multicolumn{5}{|c|}{ Bishunpur } \\
\hline 1 & 0.355 & 0.00147 & 194 & 125 \\
\hline 6 & 3.98 & 0.000756 & 140 & 110 \\
\hline 14 & 0.164 & 0.00798 & 130 & 70 \\
\hline 16 & 0.0382 & 0.000684 & $\cdots$ & -- \\
\hline 17 & 0.362 & 0.00115 & 118 & 40 \\
\hline 24 & --- & 0.000652 & 188 & 150 \\
\hline \multicolumn{5}{|c|}{ Chainpur } \\
\hline \multirow[t]{2}{*}{7} & 0.934 & 0.00976 & 113 & 63 \\
\hline & 0.823 & 0.164 & 113 & 63 \\
\hline 10 & 1.25 & 0.224 & 121 & 97 \\
\hline 14 & 0.598 & 0.0799 & 125 & 76 \\
\hline 17 & 0.571 & 0.0371 & 159 & 128 \\
\hline 19 & 5.31 & 0.0719 & 127 & 79 \\
\hline 27 & 1.97 & 0.0656 & 146 & 101 \\
\hline 28 & 0.398 & 0.00723 & 136 & 85 \\
\hline 35 & 0.104 & 0.00982 & 119 & 53 \\
\hline 38 & 0.462 & 0.0237 & 139 & 130 \\
\hline \multirow[t]{2}{*}{47} & 0.455 & 0.407 & 192 & 155 \\
\hline & & 0.14 & 192 & 155 \\
\hline \multirow[t]{2}{*}{50} & 1.45 & 0.232 & 130 & 124 \\
\hline & & 0.0476 & 1309 & 124 \\
\hline
\end{tabular}

* The $2 \sigma$ uncertainties are \pm 5 in the last digit. chondrules we separated from these meteorites are very roughly present in the proportions observed in thin sections (Sears et al., 1992), although handpicking is known to introduce a bias against the small and friable group A chondrules (Sears and DeHart, 1989).

\section{Thermoluminescence Data}

Our IL data are shown in Figs. 3-5. Data for more than one chip from a given chondrule are connected by tie-lines and illustrate the difficulties posed by the heterogeneity of these small samples. The TL, sensitivities of Semarkona chondrules range over about 3 orders of magnitude, and there is a range of $\sim 100^{\circ} \mathrm{C}$ in TLpeak temperature and $\sim 150^{\circ} \mathrm{C}$ in 'IL peak width (Fig. 3). There is no correlation between TL sensitivity and peak temperature and peak width, although seven out of nine group $\mathrm{B} 1$ chondrules plot in the lower-left half of the field occupied by the data. All but one of the group A5 and unclassified chondrules, which are often glassrich microcrystalline chondrules that we did not analyze because their fine texture, plot in the upper-right half of the field.

Figure 4 shows plots of TL sensitivity $v s$. peak temperature for Semarkona, Bishunpur, Chainpur, Dhajala and Allegan chondrules. With increasing petrographic type, the mean TL sensitivity of the chondrules increases. However, peak temperature and width show more complex data. The Bishunpur and Semarkona chondrules show similar scatter in their TL data, but for Chainpur 38 of the 44 chondrules have peak temperatures below $150^{\circ} \mathrm{C}$, and 10 have TI. sensitivities $>1.0$. In the case of Dhajala, more than half the chondrules have peak temperatures $>150^{\circ} \mathrm{C}$, and there is a negative correlation between Tl, sensitivity and peak temperature (Keck et al. (1986). The Allegan data cluster tightly with peak temperatures close to $190{ }^{\circ} \mathrm{C}$ and 'TI, sensitivities close to 10.0 .

The TI,-peak temperature and peak width data for the chondrules are compared with the two fields defined by bulk samples of type 3 ordinary chondrites (Sears et al. 1991) in Fig. 5. The lower and upper fields correspond to chondrites of petrographic types 3.3-3.5 and 3.5-3.9, respectively. The lower field is occupied by samples with feldspar in the low-temperature (ordered) form, while the upper field corresponds to samples with feldspar in the high-temperature (disordered) form (Guimon et al., 


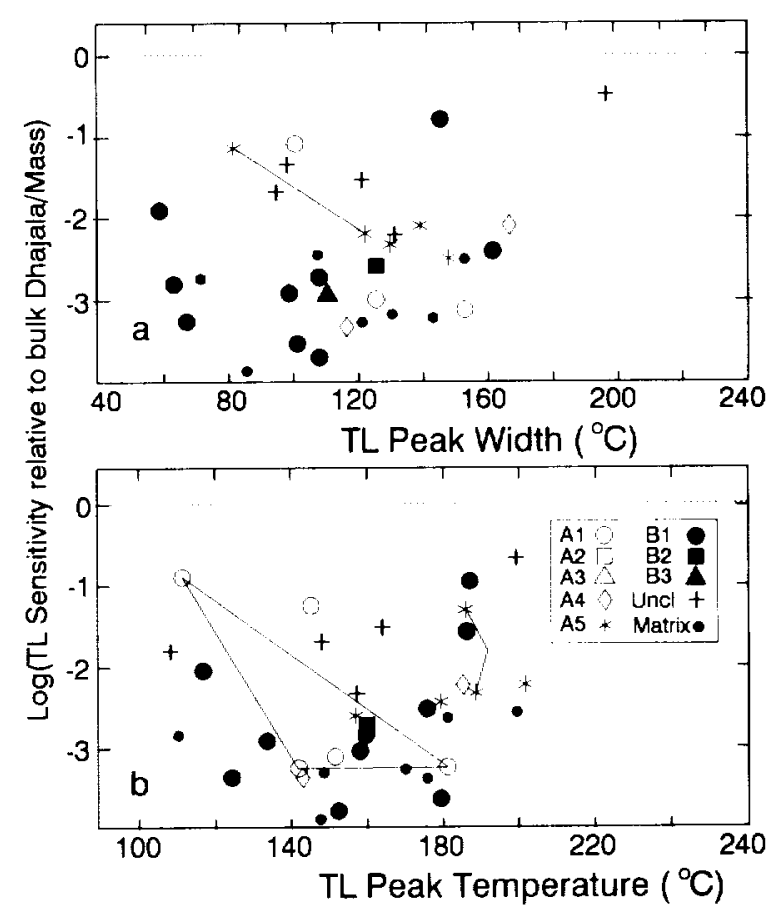

FIG. 3. Plots of TL sensitivity against peak width and peak temperature for chondrules and matrix samples from the Semarkona (type 3.0) chondrite. While there appear to be no correlations between TL sensitivity and TL-peak temperature and peak width, group BI chondrules tend to plot in the bottom-left half of the distribution, while group A5 and unclassified chondrules (which are largely glass-rich micro-crystalline chondrules) plot in the upper-right half of the field. This is consistent with group A chondrules being better crystallized and crystallizing at higher temperatures than group B chondrules. Matrix samples plot in the lower half of the TL sensitivity range but spread over the full range of 'TL peak temperatures and widths. Tie-lines connect chips from a single chondrule and illustrate the heterogeneity of these small samples.
1985). Chondrules from the type 3.0-3.1 chondrites straddle the two fields, while Chainpur chondrules mainly occupy the lower field or plot between the fields. Dhajala chondrules plot in a field slightly displaced to the right of the type 3.5-3.9 field or between the fields. Allegan chondrules (with two exceptions) plot in a tight cluster in the upper field.

Matrix samples from Semarkona, Bishunpur and Chainpur are also shown in Figs. 3 and 4. The TL data for the matrix of a given meteorite show similar spread to that of chondrules, except that in the case of Semarkona matrix, TL sensitivities are in the lower half of the chondrule range.

\section{Hydrogen Isotopes and Water Content}

Previous stepped pyrolysis measurements for Semarkona yield water with roughly terrestrial $\mathrm{D} / \mathrm{H}$ at temperatures $<200^{\circ} \mathrm{C}$ but with considerable D enrichments (up to $4500 \%$ ) in the water released at $600-1000{ }^{\circ} \mathrm{C}$ (McNaughton et al., 1981, 1982; Yang and Epstein, 1983; Iinton et al., 1983). A fall in D/H ratio for water released in the highest temperature step may indicate a third component. The present six-step pyrolysis of the 20 -mg Semarkona sample produced results in good agreement with literature data, even though earlier workers used $\sim 150$-mg samples (Fig. 6a-d). Chondrule masses are too small for six-step pyrolysis. However, two-step pyrolysis $\left(\leq 200^{\circ} \mathrm{C}\right.$ and $200-1000^{\circ} \mathrm{C}$ ) of a 1 -mg sample (Fig. 6e) is apparently sufficient to measure the quantity and isotopic value of the deuterium-rich component

Our water content and D/H data are shown in Table 4 and Fig. 7. As with whole-rock data, most of the water was released in the low-temperature step and had approximately terrestrial $\mathrm{D} / \mathrm{H}$ values. The high-temperature steps released relatively small amounts of water $(<0.2 \mathrm{wt} \%)$ with a wide range of $\delta \mathrm{D}$ values. The average water content of the chondrules and $\delta 1$ ) values during the hightemperature release from the chondrules were $0.12 \pm 0.02 \mathrm{wt} \%$ and $3890 \pm 500 \%$, respectively (arithmetic means $\pm 1 \sigma$ ). In five cases, the amount of water released was below our $0.017 \mu \mathrm{mol}$ detection limit.

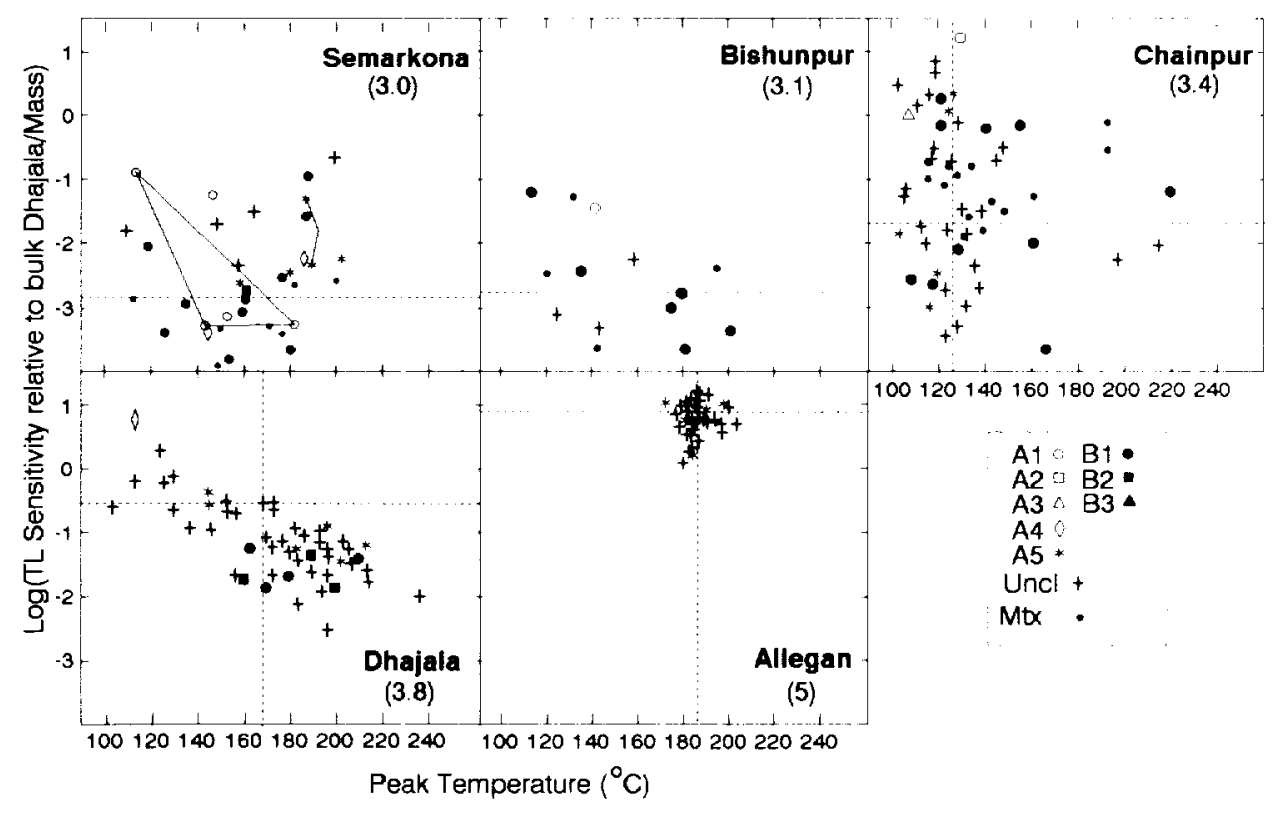

FIG. 4. Plots of TI sensitivity against TL-peak temperature for chondrules from five ordinary chondrites of a range of petrographic type. The cross-hairs refer to the values for the bulk sample. (Because of low signal and sample heterogeneity, it is not meaningful to assign peak temperatures to the bulk Semarkona and Bishunpur). The mean TI, sensitivities of the chondrules increase with petrographic type, and there are systematic changes in peak temperatures. The data for Semarkona and Bishunpur scatter fairly randomly, but Chainpur chondrules tend to have peak temperatures $<150^{\circ} \mathrm{C}$. More than half the IShajala chondrules have peak temperatures $>150{ }^{\circ} \mathrm{C}$, and Dhajala chondrules show a negative correlation between TL sensitivity and peak temperature. Allegan chondrules form a tight cluster with peak temperatures of about $190^{\circ} \mathrm{C}$ and $\mathrm{TL}$ sensitivities close to 10.0. Matrix data are also plotted for Semarkona, Bishunpur and Dhajala. These data are consistent with metamorphism being the major factor in determining the $\mathrm{TL}$ trends shown by type 3 ordinary chondrites. 
FIG. 5. Plots of TL-peak temperature vs. peak width for chondrules from ordinary chondrites. The two fields refer to type 3 ordinary chondrites and samples annealed in the laboratory (Sears et al., 1991; Guimon et al., 1985) and are thought to be due to low- and high-lemperature feldspar in the lower-left and upper-right fields, respectively. Semarkona and Bishunpur chondrules show a correlation between these parameters but do not plot preferentially in either of the two fields. On the other hand, Chainpur chondrules plot preferentially in the low field or between the fields, and Dhajala chondrules plot in the upper field (displaced slightly to the right) or between the fields. Allegan chondrules plot in a tight cluster (two chondrules aside) in the upper field. These trends are also consistent with metamorphism being the major factor in determining the $T I$ properties of chondrules in type 3 ordinary chondrites.

All four matrix samples contained very large amounts of water $(>0.25 w \%)$ but only moderate $D / \mathrm{H}$ ratios $(\leq+3000 \%)$. The high D/H observed for the chondrules cannot, therefore, be attributed to contamination with the present matrix. It is possible that chondrule $\mathrm{SC}$ 17, with conspicuously high water content but moderate $\mathrm{D} / \mathrm{H}$ value, might have contained adhering matrix although no matrix was present on the corresponding petrographic sections.

\section{Volatile/Mobile Trace Elements}

Our RN $\Lambda \Lambda$ data appear in Fig. 8. The elements are sorted by cosmochemical group and within each group are plotted in order of increasing element mobility as determined from laboratory heating experiments on Krymka (Ikramuddin et al., 1977). In view of the generally low abundance and heterogeneity of these elements, the patterns obtained are surprisingly reproducible from chondrule-tochondrule regardless of chondrule group, although not all the groups are adequately represented. Lithophile-element abundances are higher than siderophiles, which are higher than chalcophiles. Lithophile-element abundances decrease with increasing element mobility, whereas chalcophile-clement abundance increases with

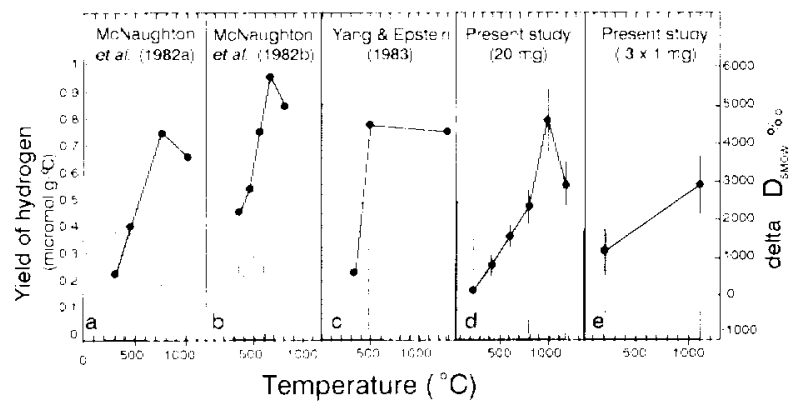

Fig. 6. A comparison of the abundance and isotopic composition of $\mathrm{H}$ released during stepped pyrolysis of bulk Semarkona samples. Blocks a-c summarize literature data while blocks $\mathrm{d}$ and e summarize data obtained in the present study. Data for six-step pyrolysis of a $20 \mathrm{-mg}$ sample are shown in Fig. $6 \mathrm{~d}$, and the mean of three $1-\mathrm{mg}$ samples analyzed in two steps are shown in Fig. 6c. All data indicate the presence of large amounts of a component with terrestrial composition, which is released $<400{ }^{\circ} \mathrm{C}$, and a D-rich component, which is released $>400^{\circ} \mathrm{C}$ : increasing element mobility. Siderophile elements are either independent of element mobility or, in some cases, increase with mobility.

\section{DISCUSSION}

We are primarily interested in the extent to which aqueous alteration and metamorphism, separately or together, have affected the type 3.0-3.3 ordinary chondrites. We will first consider evidence for metamorphism, then primary variations and finally aqueous alteration.

\section{Metamorphic Properties}

Metamorphism caused three major changes to the chondrules. (1) Mineral and phase compositions homogenized in the manner described by Dodd (1969), Dodd et al. (1967), Jones and Scott (1989), Jones (1990), McCoy et al. (1991), DeHart et al. (1992) and others. (2) Chondrules did not act as closed systems but underwent major compositional changes during metamorphism. As a result, there was eventually almost complete chondrule-tochondrule uniformity of bulk and mineral composition (Sears et al., 1992). Chondrules, whose mesostases originally ranged from quartz- to anorthite-normative, became oligoclase-nonnative with metamorphism. Similarly, chondrule olivines lost $\mathrm{Ca}$ and gained Fe during metamorphism. (3) Metamorphism produced new feldspar by crystallization of chondrule glass (Van Schmus and Wood, 1967). This form of "secondary" feldspar was ordered or disordered depending on the temperature of crystallization; production of ordered-feldspar from disordered-feldspar is kinetically difficult (McKie and McConnell, 1963).

The TL sensitivity of our samples is governed primarily by the amount of feldspar present, while the temperature and width of the induced TL peak are determined by the relative abundances of high- and low-temperature forms of feldspar (disordered and ordered, respectively; Guimon et al., 1985, 1986, 1988). Composition has a major effect on $\mathrm{TL}$ sensitivity by affecting the spectrum of the light (Batchelor and Sears, 1989) but apparently only has a minor effect on TL-peak temperature and width data. l'agioclase-normative mesostases produce $\mathrm{II}$, peaks at 
TABLE 4. Water released, and its H-isotopic composition, during two-step pyrolysis of chondrules and matrix samples from the Semarkona type 3.0 ordinary chondrite.

\begin{tabular}{|c|c|c|c|c|c|c|}
\hline \multirow[b]{2}{*}{$\#$} & \multirow[b]{2}{*}{$\begin{array}{l}\text { Mass } \\
(\mathrm{mg})\end{array}$} & \multicolumn{2}{|r|}{$200^{\circ} \mathrm{C}$} & \multicolumn{2}{|c|}{$1100^{\circ} \mathrm{C}$} & \multirow[b]{2}{*}{$\begin{array}{l} \pm 2 \sigma \\
(\% 0)\end{array}$} \\
\hline & & $\begin{array}{l}\mathrm{H}_{2} \mathrm{O}^{*} \\
\left(\mathrm{wt}^{\circ} \%\right)\end{array}$ & $\frac{\delta \mathrm{D} \pm}{\left(\%_{0}\right)} 20$ & $\begin{array}{l}\mathrm{H}_{2} \mathrm{O}^{*} \\
(\mathrm{wt} \%)\end{array}$ & $\delta \mathrm{D}$ & \\
\hline \multicolumn{7}{|c|}{ Chondrules } \\
\hline 1 & 1.3731 & $<0.022$ & $600 \pm 200$ & $<0.022$ & +4250 & \pm 1200 \\
\hline 2 & 1.0690 & $<0.028$ & $\cdot 3200 \pm 650$ & 0.122 & +1800 & \pm 600 \\
\hline 6 & 1.0118 & $<0.030$ & $+1120 \pm 500$ & 0.247 & +1800 & \pm 600 \\
\hline 9 & 0.0789 & $<0.382$ & $-780 \pm 200$ & $<0.382$ & +740 & $\neq 800$ \\
\hline 15 & 0.8274 & $<0.036$ & $+750+350$ & $\therefore 0.036$ & +2650 & \pm 1200 \\
\hline 17 & 0.0869 & 1.266 & $+480 \pm 300$ & 1.036 & +3600 & \pm 900 \\
\hline 19 & 0.0426 & $<0.704$ & $+650 \pm 300$ & $<0.704$ & +380 & +400 \\
\hline 20 & 1.5291 & $<0.020$ & $-400+300$ & $\div 0.020$ & +3200 & \pm 1400 \\
\hline 28 & 0.3522 & $<0.085$ & $+150+300$ & 0.142 & +4320 & \pm 1000 \\
\hline 34 & 0.1739 & 0.345 & $+900 \pm 400$ & 0.173 & +2800 & \pm 1600 \\
\hline 36 & 0.4820 & $<0.062$ & $+550 \pm 400$ & 0.062 & +5500 & \pm 1000 \\
\hline 40 & 0.3570 & 0.252 & $+480+300$ & 0.3641 & +4150 & \pm 800 \\
\hline 42 & 0.4902 & $<0.061$ & 100,300 & $<0.061$ & +6200 & \pm 1300 \\
\hline 46 & 0.5300 & 0.189 & $\ldots$ & 0.208 & +2000 & \pm 1300 \\
\hline 47 & 0.3367 & $<0.089$ & $+1300 \pm 400$ & 0.089 & +5000 & \pm 900 \\
\hline 49 & 0.0591 & $<0.507$ & $+550 \perp 300$ & $<0.507$ & +850 & \pm 400 \\
\hline 54 & 1.9223 & 0.052 & $620 \pm 200$ & 0.073 & +5100 & \pm 1100 \\
\hline 58 & 0.3143 & 0.095 & $+3300 \pm 700$ & 0.095 & +6620 & \pm 1500 \\
\hline 65 & 0.9666 & 0.103 & 2650 : 600 & 0.103 & +7380 & \pm 1200 \\
\hline 70 & 0.2698 & 0.556 & $+1850+450$ & 0.556 & +5680 & \pm 1300 \\
\hline 71 & 0.0952 & $<0.315$ & $300 \pm 250$ & 0.315 & +280 & \pm 300 \\
\hline 72 & 1.2479 & 0.031 & $+1700 \neq 500$ & 0.165 & +6050 & \pm 1000 \\
\hline \multicolumn{7}{|c|}{ Chondrule Mean } \\
\hline & 0.6317 & 0.083 & $840 \pm 130$ & 0.121 & +3890 & \pm 500 \\
\hline \multicolumn{7}{|c|}{ Matrix Samples } \\
\hline 4 & 0.0900 & $<0.333$ & $0 \pm 300$ & 0.330 & +1300 & +1300 \\
\hline 16 & 0.6208 & 0.097 & $+1100=400$ & $<0.048$ & +3000 & \pm 900 \\
\hline 18 & 0.4488 & 0.624 & $+750 \pm 350$ & 0.758 & +2250 & \pm 600 \\
\hline 40 & 0.2082 & 1.057 & $+1450 \therefore 400$ & 2.546 & +3000 & \pm 800 \\
\hline \multicolumn{7}{|c|}{ Matrix mean } \\
\hline & 0.3430 & 0.43 & $+1010 \pm 160$ & 0.68 & $\div 2670$ & \pm 520 \\
\hline
\end{tabular}

* The 20 uncertainties on the water are $+10 \%$ of the quoted amount.

temperatures of $\sim 100-300{ }^{\circ} \mathrm{C}$ when anorthitic (group $\Lambda$ chondrules), and $-100{ }^{\circ} \mathrm{C}$ when albitic in composition (group $\mathrm{B}$ chondrules) (Ninagawa et al, 1991, 1992; Matsunami et al., $1992 \mathrm{a}, \mathrm{b})$. Thermoluminescence glow curves of the sort attributed by Matsunami et al. (1992a) to cristobalite-produced by mesostases containing 84-99 wt $\% \quad \mathrm{SiO}_{2}$-were only rarely observed during the present work. With these generalizations in mind, it is helpful to discuss the TL trends as a function of petrographic type starting with the highest types.

The chondrules in Allegan are compositionally uniform, and their mesostases well crystallized. The TL sensitivity of Allegan chondrules is relatively high, and peak temperature and widths plot in a tight cluster between the fields corresponding to high and low feldspar (Figs. 3-5). We, therefore, conclude that all the Allegan chondrules contain the same mixture of high and low feldspar, consistent with the chondrules experiencing the same thermal history (involving high levels of metamorphism) and responding uniformly during cooling. 'This requires uniform composition of all the chondrules.

This is not the case for meteorites of lower petrographic type. Dhajala chondrules show negative correlations between $\mathrm{TL}$

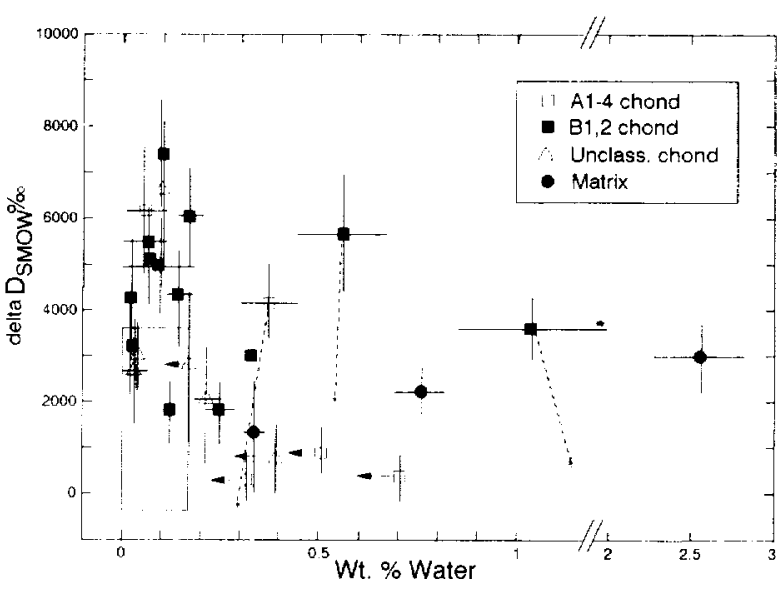

FiG. 7. Plot of $\delta \mathrm{D}$ against water released from chondrules and matrix samples from the Semarkona chondrite. Data for water released $<200^{\circ} \mathrm{C}$ (thought to be terresrial containation) plots in the shaded field. (Exceptions are three samples whose $\angle 200^{\circ} \mathrm{C}$ data are plotted as asterisks; tie lines connect these data to their high-temperature counterparts). Arrows indicate upper limits. I)ata for water released at $2001000^{\circ} \mathrm{C}$ are plotted as squares, triangles (chondrules) or circles (matrix). The very high $\delta \mathrm{D}$ values sometimes observed are not due to the presence of matrix on the chondrules, which has relatively low values of $\delta \mathrm{I}$ ). These data suggest that if the high $\delta \mathrm{D}$ component in type 3 ordinary chondrites was originally located in the matrix, it has subsequently been leached by water of terrestrial $\delta \mathrm{D}$, and only vestiges remain associated with particular chondrules.

sensitivity and peak temperature and width, demonstrating that some chondrule mesostases are crystallized more extensively than others, and that the chondrules with the most crystallized mesostases contain feldspar in the low form. Apparently, only a few of the chondrules continued to produce feldspar as they cooled through the low-temperature field from peak metamorphic temperatures. Sears et al. (1984) showed that this process was compositionally controlled, in part, although chondrule size and other local factors would also affect kinetics of crystallization and feldspar ordering.

Very few Chainpur chondrules contain feldspar in the highform, and since high-feldspar (unlike low-feldspar) forms very readily, the meteorite could never have been heated into the hightemperature field. The spread in TI, sensitivities is very large because the extent of crystallization varies considerably from chondrule to chondrule, reflecting compositional heterogeneity in the meteorite. Sears et al. (1992) showed that group $\Lambda$ chondrules respond more readily to metamorphism than do group $B$ chondrules.

The 'II data for separated chondrules from type 3 ordinary chondrites ase therefore readily understood in terms of metamorphic changes occurring after their formation and incorporation into the meteorite. On the other hand, it seems highly unlikely that the mineralogical trends observed in chondrules could be the result of aqueous alteration, and it seems equally unlikely that the TL, trends observed above could be the result of aqueous alteration. Guimon et al. (1988) performed hydrothermal-alteration experiments on Semarkona and Allan Iills A77214 (3.4) that provide some indication of the TI trends expected from aqueous alteration. Thermoluminescence sensitivities tend to decrease following hydrothermal alteration, but peak temperatures increase in a complex fashion, producing TI. peaks not commonly observed in the natural chondrules. This 
probably reflects preferential destruction of low-temperature peaks, a behavior quite unlike the trends observed among the type 3 ordinary chondrites where low-levels of TL sensitivity is associated with low-temperature peaks.

\section{Primary Properties}

The range of TL sensitivities, peak temperatures and peak widths shown by the Semarkona and Bishunpur chondrules give no indication of correlation. This suggests that feldspar is present in varying amounts and in the high- and low-forms, in varying proportions.

Cooling rates at high temperatures during chondrule formation were very rapid, $100-1000^{\circ} \mathrm{C} / \mathrm{h}$ (Hewins, 1988), so that the cooling phase, which resulted in the formation of feldspar, must have occurred at low temperatures, perhaps during blanketing in dust or regolith in order that significant amounts were in the low form. Since most other chondrules (mainly the unclassified and group A5 chondrules because data for the others are scarce) plot in the upperright half of the distribution in Fig. 3, compared to group B, these chondrules are more crystallized and contain a greater proportion of high-feldspar. Consistent with this, group B chondrules contain mesostasis compositions, indicating considerable supercooling (Jones, 1990; DeHart et al., 1992).

Like the other group A chondrules, group A5 chondrules avoided supercooling, but they are Na-rich. If these chondrules cooled slowly enough to avoid supercooling, they would, like the other $\mathrm{A}$ groups, have lost $\mathrm{Na}$. We suspect that they acquired $\mathrm{Na}$ by recondensation. Matsunami et al. (1992b) describe a large group A chondrule in which the outer regions of the mesostasis are volatilerich; they ascribe this to recondensation of volatiles in such an environment. Chondrule 13c of DeHart et al. (1992) is another example. In any event, their TL data are consistent with relatively slow cooling with some crystallization in the high-temperature field of feldspar.

The observed TL trends could not result from the effects of aqueous alteration of individual Semarkona or Bishunpur chondrules. As discussed above, Guimon et al. (1988) laboratory data indicate that aqueous alteration at low temperatures does not produce low-temperature feldspar from high-temperature feldspar (i.e., decrease the TL peak temperature from 200 to $100^{\circ} \mathrm{C}$ ), nor does it produce high-temperature feldspar from low-feldspar (which would result in a $100^{\circ} \mathrm{C}$ temperature increase)

The most striking aspect of the present data is that none of the present chondrules are significantly depleted in highly mobile chalcophile and lithophile elements; $\mathrm{In}, \mathrm{Tl}, \mathrm{Bi}$ and $\mathrm{Cd}$ are remarkably close to $\mathrm{CI}$ proportions in all the chondrule groups, including group A. Ikramuddin et al. (1977) found that these elements were particularly mobile during laboratory heating and that they have especially low activation energies for evaporative loss. Group Al chondrules in Semarkona are strongly depleted in volatile elements- $\mathrm{Na}$ and $\mathrm{K}$ typically by $60 \%, \mathrm{Mn}$ and $\mathrm{Cr}$ by around $40 \%$, and Si by $10-20 \%$ (Lu et al., 1990; Lu, 1992).

To a first approximation, abundances are governed by mineralogical factors. Metal and sulfides are depleted and silicates enriched in the chondrules. The resulting element-abundance patterns are well known. However, the patterns observed within

TABLE 5. Trace element data for chondrules from type 3 ordinary chondrites.

\begin{tabular}{|c|c|c|c|c|c|c|c|c|c|c|c|c|c|c|c|c|}
\hline & $\begin{array}{l}\text { Chond } \\
\text { Class }^{f}\end{array}$ & $\begin{array}{c}\mathrm{Ag} \\
\mathrm{ng} / \mathrm{g}\end{array}$ & $\begin{array}{c}\mathrm{Au} \\
\mathrm{ng} / \mathrm{g}\end{array}$ & $\begin{array}{c}\mathrm{Bi} \\
\mathrm{ng} / \mathrm{g}\end{array}$ & $\begin{array}{c}\mathrm{Cd} \\
\mathrm{ng} / \mathrm{g}\end{array}$ & $\begin{array}{c}\mathrm{Co} \\
\mu \mathrm{g} / \mathrm{g}\end{array}$ & $\begin{array}{c}\mathrm{Cs} \\
\mathrm{ng} / \mathrm{g}\end{array}$ & $\begin{array}{c}\mathrm{Ga} \\
\mu \mathrm{g} / \mathrm{g}\end{array}$ & $\underset{\mathrm{In} / \mathrm{g}}{\mathrm{In}}$ & $\begin{array}{c}\mathrm{Rb} \\
\mu \mathrm{g} / \mathrm{g}\end{array}$ & $\begin{array}{c}\mathrm{Sb} \\
\mathrm{ng} / \mathrm{g}\end{array}$ & $\begin{array}{c}\mathrm{Se} \\
\mu \mathrm{g} / \mathrm{g}\end{array}$ & $\begin{array}{c}\mathrm{Te} \\
\mu \mathrm{g} / \mathrm{g}\end{array}$ & $\begin{array}{c}\mathrm{Tl} \\
\mathrm{ng} / \mathrm{g}\end{array}$ & $\begin{array}{c}\mathrm{U} \\
\mathrm{ng} / \mathrm{g}\end{array}$ & $\begin{array}{l}\mathrm{Zn} \\
\mu \mathrm{g} / \mathrm{g}\end{array}$ \\
\hline \multicolumn{17}{|c|}{ Semarkona } \\
\hline 39 & A5 & 35 & 31 & 8.9 & 130 & 110 & 78 & 0.59 & 92 & 9.0 & 62 & 3.5 & $<0.02$ & 16 & 16 & 4.1 \\
\hline 40 & A5 & 26 & 37 & 22 & 380 & 140 & 2100 & 1.3 & 350 & 5.8 & 87 & 2.8 & 0.049 & 33 & 24 & 13 \\
\hline 46 & $\cdots$ & 80 & 6.2 & 410 & 120 & 100 & 430 & 13 & 39 & 33 & 120 & 0.58 & $<0.20$ & 98 & 15 & 45 \\
\hline 47 & Al-4 & 210 & 110 & $<190$ & 3600 & 500 & 300 & 6.6 & 280 & 8.1 & 2800 & 5.4 & 1.5 & 160 & 250 & 69 \\
\hline 51 & A5 & 8.9 & 3.6 & 52 & 470 & 86 & 17 & 0.46 & 37 & 0.35 & 52 & 0.17 & $<0.36$ & 67 & 140 & 1.9 \\
\hline 60 & $\mathrm{Bl}$ & 230 & 4.9 & $<260$ & 5400 & 240 & 260 & 1.1 & 160 & 5.8 & 3000 & 0.36 & 4.1 & 220 & 1400 & 50 \\
\hline 65 & $\mathrm{~A} 3$ & 12 & 23 & 6.3 & 940 & 120 & 190 & 1.9 & 60 & 3.2 & 300 & 2.7 & 0.20 & 13 & 14 & 17 \\
\hline 70 & B1 & 89 & 15 & 120 & 1600 & 140 & 170 & 2.1 & 1700 & 3.2 & 530 & 3.1 & 0.11 & 64 & 260 & 46 \\
\hline \multicolumn{17}{|c|}{ Bishunpur } \\
\hline 3 & $\mathrm{Bl}$ & 84 & 17 & 37 & 920 & 100 & 590 & 3.2 & 13 & 9.4 & 270 & 1.8 & 1.3 & 120 & 150 & 21 \\
\hline 7 & -- & 140 & 11 & 520 & 1500 & 93 & 360 & 2.6 & 260 & 2.8 & 61 & 1.7 & 0.067 & 150 & 450 & 24 \\
\hline 12 & B1 & 870 & 130 & 17 & 810 & 540 & 180 & 5.5 & 980 & 4.2 & 100 & 8.3 & 0.13 & 990 & 41 & 45 \\
\hline 18 & $\mathrm{BI}$ & 90 & 62 & $<3.2$ & 480 & 370 & 230 & 4.1 & 230 & 35 & 62 & 8.5 & 0.14 & 80 & 160 & 30 \\
\hline 21 & A4 & 1100 & 65 & $<20$ & 7700 & 350 & 630 & 1.2 & 10000 & 4.1 & 630 & 3.9 & 1.1 & 380 & 250 & 69 \\
\hline 29 & $A 3$ & 230 & 150 & $<40$ & 5000 & 790 & 350 & 4.9 & 15000 & 15 & 400 & 12 & 0.39 & 2000 & 260 & 56 \\
\hline 30 & $B 1,2$ & 2500 & 99 & $<18$ & 11000 & 390 & 880 & 3.1 & 73000 & 9.9 & 2300 & 7.3 & $<0.84$ & 1400 & 310 & 440 \\
\hline \multicolumn{17}{|c|}{ Chainpur } \\
\hline 39 & -- & 39 & 140 & 330 & 73 & 150 & 390 & 2.6 & 64 & 3.1 & 70 & 6.0 & 0.09 & 180 & 170 & 19 \\
\hline 41 & $\mathrm{BI}$ & 3300 & 95 & 640 & 5800 & 110 & 790 & 2.6 & 390 & 6.8 & 1600 & 0.62 & 4.8 & 240 & 320 & 38 \\
\hline 42 & $\mathrm{Bl}, 2$ & 240 & 50 & 97 & 920 & 91 & 150 & 1.7 & 41 & 3.7 & 400 & 1.9 & 0.45 & 200 & 130 & 23 \\
\hline 43 & $\mathrm{Bl}$ & 550 & 25 & 480 & 1700 & 110 & 280 & 1.8 & 140 & 10 & 1300 & 1.8 & 1.0 & 52 & 160 & 93 \\
\hline 44 & $\mathrm{Bl}$ & 58 & 62 & 33 & 400 & 400 & 87 & 1.2 & 21 & 3.5 & 230 & 7.6 & 0.22 & 230 & 170 & 23 \\
\hline 45 & A5 & 110 & 18 & 72 & 43 & 140 & 240 & 3.8 & 23 & 9.3 & 100 & 2.4 & 0.26 & 76 & 110 & 21 \\
\hline 60 & $\mathrm{~B} 1$ & 120 & 15 & 21 & 1200 & 450 & 400 & 8.8 & 300 & 74 & 150 & 4.1 & $<0.38$ & 140 & 4100 & 11 \\
\hline
\end{tabular}

\footnotetext{
* Uncertainties are assumed to be those established from replicate analysis of 5-mg Murchison samples (Zolensky et al., 1992): $\leq 15 \%$ for $\mathrm{Ag}, \mathrm{Au}, \mathrm{Co}, \mathrm{Cd}, \mathrm{Cs}, \mathrm{Rb}, \mathrm{Zn}$; a factor of two for $\mathrm{Sb}$, and $33 \%$ for all other elements.

$\ddagger$ Electron microprobe and cathodoluminescence data are not available for three chondrules which are therefore unclassified.
} 
the siderophile and lithophile element groups (i.e., the decrease in lithophile abundance and the increase in chalcophile element abundances with increasing mobility) have not previously been observed. The lithophile-element depletion clearly indicates evaporative loss, presumably during chondrule formation. The increase in chalcophile elements, sometimes also observed among the siderophile elements, apparently indicates that the most mobile elements are recondensing on the chondrules or in the chondrule rims. Huang et al. (1993) recently proposed that the Fe- and FeSrich layers in the rims of certain chondrules were the result of evaporation of volatiles from the chondrules and recondensation in the outer portions or rims of the chondrules. Especially noteworthy in the present case is that all chondrules are displaying this effect, although Huang et al. found that it was most important for group A chondrules. Group $A$ chondrules, which are those that behaved as open systems during chondrule formation, display this effect most markedly, but apparently the most labile elements show this effect in all groups.

One reviewer invoked an alternative scenario involving multiple heating events. In this scenario, chondrules are partly to completely volatilized in the chondrule-forming event and, after cooling, acquire a fine-grained coating of matrix materials rich in labile chalcophile- and siderophile-trace elements. According to this scenario, during subsequent solid-state reheating, some of the most mobile of these trace elements would be vaporized, while another portion would diffuse into the chondrule. 'This process could then result in chondrules rimmed by volatile-rich materials.

We do not find this construct to be at all credible, experimentally or theoretically. There is no evidence that highly labile trace elements diffuse into condensed phases in chondrites on heating. Highly labile elements are not concentrated in a single phase (Lipschutz and Woolum, 1988), and data from numerous studies of naturally annealed chondrites indicate that these elements are simply vaporized (Walsh and Lipschutz, 1982; Huston and Lipschutz, 1984; Paul and Lipschutz, 1989). Experimentally determined activation energies for vaporization of the solids are quite low (Lipschutz and Woolum, 1988). Highly labile trace elements in chondrule rims are in an ideal location to be vaporized since they are already at grain boundaries. Finally, there is evidence for recondensation of highly labile trace elements onto

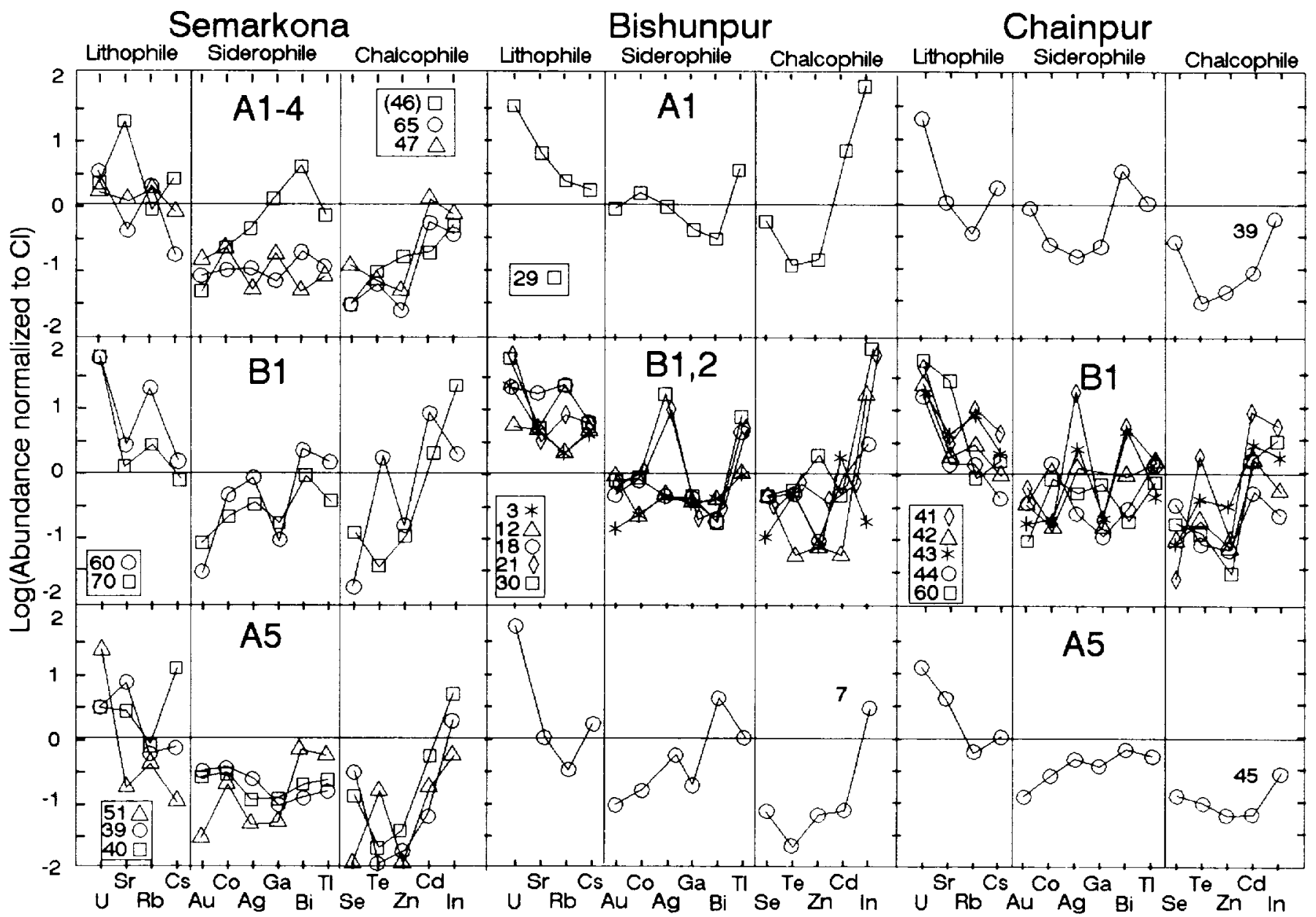

FIG. 8. Plots of the CI-normalized abundances of volatile/mobile elements in chondrules determined by radiochemical neutron activation. The numbers give the chondrule identification. Within the cosmochemical groups, elements are plotted in order of increasing mobility during laboratory heating experiments (Ikrammudin et al., 1977). In addition to the trend lithophiles $>$ siderophiles $>$ chalcophiles, the lithophiles decrease while the chalcophile (and sometimes siderophile) elements increase in abundance with increasing mobility. The decrease in abundance with volatility shown by the lithophiles reflects evaporative loss. However, the highly labile elements seem to have recondensed, and the chondrules are now enriched in these elements, perhaps associated with the metal- and sulfide-rich rims. 
meteorites of lunar origin and eucrites (Kaczaral et al., 1986; Lindstrom et al., 1991; Paul and Lipschutz, 1989).

Thus, it scems that the elemental-abundance patterns for the chondrules are readily interpreted in terms of chondrule formation processes and are difficult or impossible to reconcile with redistribution during aqueous or thermal alteration.

Like previous workers who have analyzed olivine and mesostasis compositions in chondrules of type 3 ordinary chondrites (Tsuchiyama et al, 1980; Taylor and Cirlin, 1986; Jones and Scott, 1989), we found values of $\mathrm{K}_{\mathrm{D}}$ $\left((\mathrm{FeO} / \mathrm{MgO})_{\mathrm{ol}} /(\mathrm{FeO} / \mathrm{MgO})_{\text {melt }}\right)$ well below the value of 0.3 determined in experimental systems by Roeder and Emslie (1970). Taylor and Cirlin (1986) suggested that these low values reflected higher crystallization temperatures for the low-Fe chondrules while 'Tsuchiyama et al. (1980) attributed low $\mathrm{K}_{\mathrm{D}}$ values to steep $\mathrm{Fe}$ gradients in the olivine. However, we observe that values $<0.3$ are independent of $\mathrm{Fe}$ content (Fig. 9), and we suspect that these low $\mathrm{K}_{\mathrm{I}}$ values are the result of the melt having had plagioclase-rich compositions, as suggested by Jones and Scott (1989). While $\mathrm{K}_{\mathrm{D}}$ values are $<() .3$ for chondrites of the lowest petrographic type, they rapidly approach 1.0, and the olivines approach their uniform $\mathrm{FeO}$ values with increasing metamorphism. Semarkona appears to lie at one end of the type 3 ordinary chondrite continuum.

Another important primary property of the chondrules is that a significant number of them display high $\mathrm{D} / \mathrm{H}$ ratios. There is considerable evidence for changes in isotopic and elemental composition during chondrule formation (Clayton et al., 1983, 1985, 1991; Lu, 1992; Rubin et al., 1990). However, Robert et al. (1987) rejected the idea that the high D/H ratios were produced during chondrule formation since unpublished $\mathrm{C}$ - and $\mathrm{N}$-isotopic data for chondrules show no evidence for fractionation and because there is no correlation between $\delta \mathrm{D}$ and chondrule abundance. In any event, both I) and II would almost certainly have been entirely lost during chondrule formation.

\section{Aqueous Alteration}

Both Robert et al. (1987) and Yang and Epstein (1983) also suggested that a component with terrestrial $\mathrm{D} / \mathrm{H}$ was located in the inter-chondrule matrix and associated with phyllosilicates.

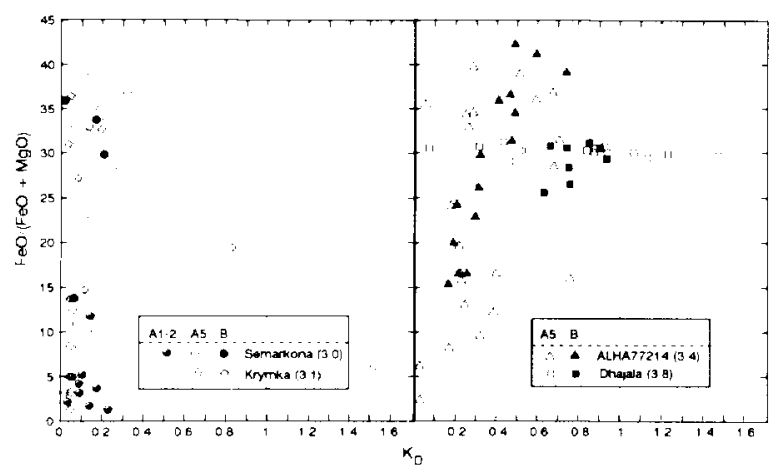

FIG. 9. Plots of Fe-number $(\mathrm{FeO} /(\mathrm{FeO}+\mathrm{MgO}))$ for olivine vs, of $\mathrm{K}_{\mathrm{D}}$ $\left((\mathrm{FeO} / \mathrm{MgO})_{\mathrm{ol}} /\left(\mathrm{FeO} / \mathrm{MgO}_{\text {melt }}\right)\right.$ for the mesostasis (assumed to be "melt") for chondrules from type 3 ordinary chondrites. The $\mathrm{K}_{\mathrm{D}}$ values approach 1.0 with increasing metamorphism, while chondrules from the most unmetamorphosed chondrites have $K_{D}$ values less than the cquilibrium value of 0.33 , independent of Fe-number. These data suggest that (1) values of $K_{D}>0.3$ are indicative of metamorphic redistribution of $\mathrm{Fe}$ and (2) values $<0.3$ are independent of chondrule $\mathrm{Fe}$, contrary to suggestions that the Fe content of the olivine affects $\mathrm{K}_{\mathrm{D}}$.
McNaughton et al. $(1981,1982)$ found that the highest $\delta \mathrm{D}$ is released at $550-650{ }^{\circ} \mathrm{C}$ during step-wise heating, which corresponds to the temperature range for release of bound water from smectite (Hutchison et al., 1987). It is possible that the D from an organic-carrier phase exchanged with $H$ in the earliest formed smectite and that the later formed smectite is isotopically "normal." Yang and Epstein (1983) suggested that the present low $\mathrm{D} / \mathrm{H}$ of the matrix may be due to exchange with water at temperatures of $\geq 200^{\circ} \mathrm{C}$. Alexander et al. (1989a) suggested that aqueous alteration occurred at temperatures $<260^{\circ} \mathrm{C}$. We suggest that perhaps the exotic high-D component was originally located in the matrix but, following leaching by water with near-terrestrial $\mathrm{D} / \mathrm{H}$, the only vestiges of original high-D component remaining are now located in cracks in chondrules and in rims.

Our TL data provide at best only weak evidence for extensive aqueous alteration of the matrix. It seems fairly clear that Semarkona and Krymka contain a great many potential TI. phosphors, while the IL of Chainpur matrix samples has peak temperatures and widths similar to Chainpur chondrules, where the feldspar is in the low form. The generally much smaller spread in TL sensitivities displayed by the matrix could reflect the homogenization of TL properties by destruction of feldspar; the aqueous alteration produced in the Guimon et al. (1988) experiments also resulted in a small spread in TL sensitivities. Alternatively, the uniform matrix TL sensitivities could reflect thorough mixing of fine grains prior to lithification of the meteorite. Guimon et al. experiments also showed that aqueous alteration preferentially destroys the low-temperature $\mathrm{TL}$ and thereby increases apparent peak temperature. There is little or no evidence for such a trend in the TL data for Semarkona matrix.

\section{SUMMARY AND CONCLUSIONS}

The question of the relative importance of aqueous alteration and metamorphism in the early history of type 3 ordinary chondrites is related to the question of the "primitiveness" of the matrix-a question on which little consensus exists (Scott et al., 1988). Apparently, while some primitive properties may be present, they are difficult to distinguish from metamorphic and aqueous alteration effects, especially since brecciation appears to have been common.

It seems that the chondrules were susceptible to thermal metamorphism but resistant to aqueous alteration. Therefore, they constitute a metamorphic series. However, the matrix history is more complicated. The matrix of Semarkona is unique among the ordinary chondrites and similar to that of the primitive members of other chondrite groups by having abundant uniformly fine-grained forsterite. Ikeda et al. (1981), Kurat (1969) and Scott et al. (1988) also observed that the matrices of ordinary chondrites resembled those of $\mathrm{CM}$ chondrites. We suggest that little nebular dust survives in Semarkona (3.0) and Bishunpur (3.1), although grains of interstellar material ( $\mathrm{SiC}$, diamond and, perhaps, organics) are present. On the other hand, it is clear from a wide varicty of data that the matrix in meteorites of type $>3.3$ has undergone significant textural and compositional changes during metamorphism.

Even the most unaltered nebular material (other than the chondrules), namely the matrices of the Krymka and the type 3.23.3 chondrites, has experienced significant levels of metamorphism. Nevertheless, they are the most fertile hunting grounds for primitive nebular material. While there are a great many known ordinary chondrites, most type $3.1-3.3$ chondrites are finds 
and have been subjected to (sometimes considerable) terrestrial alteration. Included in this category are a large number of paired type 3.2 chondrites from the Lewis Cliff. Only Ngawi and St. Mary's County are observed falls. Ngawi is a regolith breccia (Sears et al., 1991) with a comminuted coarse matrix enclosing various clasts of low petrographic type material, some of type 3.3. The mineralogy of the 23-g St. Mary's County was described by Noonan et al. (1977), and Lu et al. (1989) described its CL properties, but its matrix has not yet been studied.

Acknowledgments-We are grateful to Glenn MacPherson (Smithsonian Institution) for supplying the Semarkona sample and the Natural History Museum, London, for the samples of Bishunpur and Chainpur. We are also grateful to Gary Huss, Sasha Krot and Jim Gooding for thorough and very helpful reviews and to the following for grant support NASA (NAG 9-48 to MEL and NAGW 3519 to DWGS), DOE (DE-FG07-80ER1 0725J to MEL), NSF (INT 8612744 to DWGS), SERC (GRE 16564 to CTP), and to the staff of the University of Missouri Research Reactor for irradiation assistance.

Editorial handling: K. Keil

\section{REFERENCES}

Alexander C. M. O., BARBER D. J. AND HutCHISON R. (1989a) The microstructure of Semarkona and Bishunpur. Geochim. Cosmochim. Acta $53,3045-3057$

ALEXANDER C. M. O., HUTCHISON R. AND BARBER D. J. (1989b) Origin of chondrule rims and interchondrule matrices in unequilibrated ordinary chondrites. Earth Planet. Sci. Lett. 95, 187-207.

BATCHELOR J. D. AND SEARS D. W. G. (1989) Thermoluminescence of plagioclase feldspars and implications for meteorite studies (abstract). Lunar Planet. Sci. 20, 52-53.

Clayton R. N., ONUMA N., IKEDA Y., MAYEDA T. K., HUTCHEON I. D., OLSEN E. J. AND MOLINI-VELSKO C. (1983) Oxygen isotopic compositions in chondrules in Allende and ordinary chondrites. In Chondrules and the Origins (ed., E. A. King.), pp. 37-43. Lunar and Planetary Institute, Houston, Texas.

Clayton R. N., MAYEDA T. K. AND Mol.nN-VElsko C. A (1985) Isotopic variations in solar system material. In Protostars and Planets $I I$ (eds. D. C. Black and M. S. Matthews), pp. 755-771. Univ. Arizona Press, Tucson, Arizona.

Clayton R. N., MAYEda T. K., Goswami J. N. and Olsen E. J. (1991) Oxygen isotope studies of ordinary chondrites. Geochim. Cosmochim. Acta 55, 2317-2337.

Dehart J. M., Lofgren G. E., LU J., BenotT P. H. and Sears D. W. G. (1992) Chemical and physical studies of chondrites $X$-Cathodoluminescence studies of metamorphism and nebular processes in type 3 ordinary chondrites. Geochim. Cosmochim. Acta 56, 3791-3807.

DODD R. T. (1969) Metamorphism of ordinary chondrites: A review. Geochim. Cosmochim. Acta 33, 161-203.

DODD R. T., VAN SCHMUS W. R. AND KOFFMAN D. M. (1967) A survey of the unequilibrated ordinary chondrites. Geochim. Cosmochim. Acta 31, 921-951.

FISHER I. P. AND BROWN W. F. (1971) The analysis of deuterium content of hydrogen at and below natural abundance levels. Int. J. Mass Spectrom. Ion Phys. 7, 273- 279.

GOODNG J. L. AND KEII. K. (1981) Relative abundances of chondrule primary textural types in ordinary chondrites and their bearing on chondrule formation. Meteoritics 16, 17-43.

GUMMON R. K. AND SEARS D. W. G. (1987) Thermoluminescence of separated chondrules and chondrite thermal history and cooling rates (abstract). Meteoritics 22, 396-397.

GUIMON R. K. KECK B. D., WEeKs K. S., DeHart J. AND SEars D. W. G. (1985) Chemical and physical studies of chondrites-IV: Annealing studies of a type 3.4 ordinary chondrite and the metamorphic history of meteorites. Geochim. Cosmochim. Acta 49, 1515-1524.

GUMMON R. K., SEARS D. W. G. AND LOFGREN G. E. (1986) The thermoluminescence-metamorphism relationship in ordinary chondrites: Experimental data on the mechanism and implications for terrestrial systems. Geophys. Res. Left. 13,969-972.

GUMMON R. K. LOFGRFin G. E. AND SEARS D. W. G. (1988) Chemical and physical studies of type 3 chondrites IX: Thermoluminescence and hydrothermal annealing experiments and their relationship to metamorphism and aqueous alteration in type $<3.3$ ordinary chondrites. Geochim. Cosmochim. Acta 52, 119-127.

HEWINS R. H. (1988) Experimental studies of chondrules. In Meteorites and the Early Solar System (eds. J. F. Kerridge and M. S. Matthews), pp. 661 679. Univ. Arizona Press, Tucson, Arizona.

Hinton R. W., LONG J. V. P., FAldick A. E. AND PILI.INGER C. T. (1983) Ion microprobe measurement of $\mathrm{D} / \mathrm{H}$ ratios in meteorites (abstract). Lunar Planet. Sci. 14, 313 314.

HuANG S., BENOIT P. H. AND SEARS D. W. G. (1993) Metal and sulfide in Semarkona chondrules and rims: Evidence for reduction, evaporation, and recondensation during chondrule formation (abstract). Meteoritics 28, $367-368$.

HusTON 'T. J. AND I.IPSCHUTZ M. E. (1984) Chemical studies of L chondritesIII. Mobile trace elements and ${ }^{40} \mathrm{Ar} /{ }^{39} \mathrm{Ar}$ ages. Geochim. Cosmochim. Acta 48, 1319 - 1329.

HuTCHISON R., ALEXANDER C. M. O. AND BARBER D. J. (1987) The Semarkona meteorite: First recorded occurrence of smectite in an ordinary chondrite, and its implications. Geochim. Cosmochim. Acta 51, 1875-1882.

IKEDA Y., KIMURA M., MORI H. AND TAKEDA H. (1981) Chemical compositions of matrices of unequilibrated ordinary chondrites. Proc. 6th Symp. Antarct. Meteorites, Mem. Natl. Inst. Polar Res. Spec. Issue 20, 124-144.

IKRAMUDDIN M., BINZ C. M. AND LIPSCHUTZ M. E. (1977) Thermal metamorphism of primitive meteorites-II. Ten trace elements in Krymka L3 chondrite heated at $400-1000^{\circ} \mathrm{C}$. Geochim. Cosmochim. Acta. 40, $133-142$.

JONES R. H. (1990) Petrology and mineralogy of type II, FeO-rich chondrules in Semarkona (LL3.0): Origin by closed system fractional crystallization, with evidence for supercooling. Geochim. Cosmochim. Acta 54, $1785-1802$.

JONES R. H. AND SCOTT R. H. (1989) Petrology and thermal history of type IA chondrules in the Semarkona (LL3.0) chondrite. Proc. Lunar Planet. Sci. Conf. 19th, 523-536.

KaCZARAL P. W., DENNISON J. E. AND LIPSCHUTZ M. E. (1986) Yamato 791197: A volatile trace element rich lunar highlands sample from Antarctica. Proc. Symp. Antarct. Meteorites 10th, 76-83.

KECK B. D. GUIMON R K AND SEARS D. W. G. (1986) Chemical and physical studies of type 3 chondrites VII: Annealing studies of Dhajala H3.8 chondrite and the thermal history of chondrules and chondrites. Earth Planet. Sci. Lett. 77, 419-427.

KERRIDGE J. F. AND MATTHEWS M. S. (1988) Meteorites and the Early Solar System. Univ. Arizona Press, Tucson, Arizona. 1269 pp.

KURAT G. (1969) The formation of chondrules and chondrites and some observations of the chondrules from the Tieschitz meteorite. In Meteorite Research (ed. P. M. Millman), pp. 185-190. Reidel, Dordrecht.

I.JNDSTROM M. E., MITTLEFEHLDT D. W., MARTINEZ R., LIPSCHUTZ M. E. AND WANG M. S. (1991) Geochemistry of Yamato 82192, 86032 and 793274 lunar meteorites. Proc. NIPR Symp. Antarct. Meteorites 4th, 12-32.

LIPSCHUTZ M. E. AND WOOLUM D. (1988) Highly labile elements. In Meteorites and the Early Solar System (eds. J. F. Kerridge and M. S. Matthews), pp. 462-487. Univ. Arizona Press, Tucson, Arizona.

LU J. (1992) Physical and chemical studies of chondrules from the type 3 ordinary chondrites. Ph.D. thesis, University of Arkansas at Fayetteville. $321 \mathrm{Pp}$

LU J., DEHART J. M. AND SEARS D. W. G. (1989) Cathodoluminescence properties of St. Mary's County, a type 3.3 ordinary chondrite, compared with other type 3 ordinary chondrites (abstract). Meteoritics 24, 296.

Lu J., Sears D. W. G., Keck B. D., Prinz M., Grossman J. N. AND CIAYTON R. N. (1990) Semarkona type I chondrules compared with similar chondrules in other classes (abstract). Lunar Planet. Sci. 21 , 720-721.

MatSUNAMI S Ninagawa K, KuBO H FumMURA S, YaMamoto I WADA T. AND NISHMURA H. (1992a) Silica phase as a thermoluminescence phosphor in Al.H-77214 (L3.4) chondrite. Proc. NIPR Symp. Antarct. Meteorites 5th, 270-280.

Matsunami S., Ninagawa K., Nishimura H., Kubono N., Yamamoto I., Kohata M., Wada T. AND Yamashita Y, LU J., SEARS D. W. G. AND NISHMUURA H. (1992b) Thermoluminescence and compositional zoning in the mesostasis of a Semarkona group Al chondrule and new insights into the chondrule-forming process. Geochim. Cosmochim. Acta 57. 2102-2110.

MCCOY T. J., SCOTT E. R. D., JONES R. H., KEIL K. AND TAYLOR G. J. (1991) Composition of chondrule silicates in LL3-5 chondrites and implications for their nebular history and parent body metamorphism. Geochim. Cosmochim. Acta 55, 601-619.

MCKIE D. AND MCCONNELL J. D. C. (1963) The kinetics of low-high transformation in albite I. Amelia albite under dry conditions. Mineral. Mag. 33, $581-588$. 


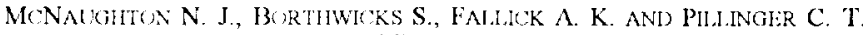
(1981) D/H ratio in unequilibrated ordinary chondrites. Nature 294, 639.641

Menatghton N. J., Faldick A. E. ANd Pildingle C. T. (1982) Deuterium enrichments in type 3 ordinary chondrites. Proc. Lunar. Planet. Sci. Conf. 13th, $J$. Geophys. Res. 87, $\wedge 297302$.

MCSWEEN II. Y. (1979) Are carbonaceous chondrites primitive or processed? A review. Rev. Geophys Space Phys. 17, 1059-1078

MOSWIiEN II. Y., SLARS 1). W. (;. ANI) IOODD R. T. (1988) Thermal metamorphism. In Meteorites and the Early Solar System (eds. J. F. Kerridge and M. S. Matthews), pp. 102113. Univ. Arizona Press, Tucson, Arizona.

MORSE: A. D. (1991) Attempts to analyze D/4 ratios of sub-micromole quantities of hydrogen: Applications in the study of ordinary chondrites. Ph.I). Thesis, 'The ( pen I Iniversity. $237 \mathrm{pp}$.

Morse A 1)., Siars D. W ( i., Gitimon R. K., Hutchison R., Wright I. P., AIIEXANIJER C. (O AND PILIINGIFR C. "l. (1987) Secondary alteration history of type 3 ordinary chondrites (abstract). Meteontics 22, $465-466$.

Morsl: A. D., SHARS I). W. (G, IITTCHSON R., GUMMON R. K., ALEXANDER C. ()., Wright I. P. AND PIIJINGeR C. T. (1988) Alteration history of type 3 ordinary chondrites (abstract). Meteoritics 23, 291.

MURSE A. 1), WRIGHT I P. ANI PILLINGLR C. T. (1993) An investigation into the cause of memory effects associated with the conversion of $\mathrm{H}_{2} \mathrm{O}$ to $\mathrm{H}_{2}$ for 1)/I measurement. (hem (teol. (Isotope (jeol) 107, 147 158.

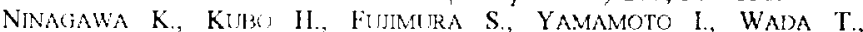
MATSINAMI S. AND NishimuRA H. (1991) Thermoluminescence characteristics and chemical compositions of mesostases in ordinary chondrites. Proc. NIP Symp. Antarct. Meteorites 4th, 344-351.

Ninagawa K., Nishimlika II., Kibono N., Yamamoto I., KoHata M., WADA T., YAMASHITA Y, I.t J., Shars D. W. G., MATSINAMI S AND NISIIMIIRA H. (1992) Thermoluminescence of chondrules in primitive ordinary chondrites, Semarkona and Bishunpur. Proc. NIPR Symp. Antarct. Meteorites 5th, 281289

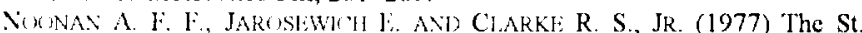
Mary's County, Maryland, chondrite. Smithson. Contrib. Earth Sci. 19 96.103.

PAUT, R. I. AND LIPSTITI\% M. L. (1989) Iabile trace elements in some Antarctic carbonaceous chondrites: Antarctic and non-Antaretic metcorite comparisons. Zeit. Naturfor. 44a, 979987.

RoBBER' I., JAVOY M. ILABU JT J. DIMON B, AND MERIVAT I (1987) Iydrogen isotope abundanees in the solar system. Part I: Unequilibrated chondrites. Geochim. ('osmochm. Acta 51, 17871805

R(JIDER P. I. AND EMSI.IE R. ]: (1970) Olivine-liquid equilibrium. Contrib. Mineral Petrol 29, 275289.

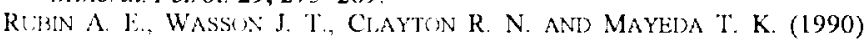
Oxygen isotopes in chondrules and coarse-grained chondrule rims from the Alende metcorite. Earth Planet. Sct. lett. 96, 247-255

SoTT E. R. 1)., BARBik D. J., ALliXANDIR C M., HUTCHSON R. AND PECK J. A (1988) Primitive material surviving in chondrites Matrix In Meteorites and the Early Solar System (eds. J. F. Kerridge and M. S Matthews), pp. 718 745. Univ, Arizona Press, Jucson, Arizona.

SEARS I). W. (3. ANI IBHART J. M. (1989) Chondrule cathodoluminescence and composition: Implications for (1) metamorphism and aqueous alteration in low type 3 ordinary chondrites and (2) selection effects in chondrule studies (abstract). Meteoritics 24, 325 .

SEARS D. W. G. AND DODD R. T. (1988) Overview and classification of meteorites. In Meteorites and the Early Solar System (eds. J. F. Kerridge and M. S. Matthews), pp. 3-31. Univ. Arizona Press, Tucson, Arizona.

SEARS D. W. G. AND WEEKS K. S. (1983) Chemical and physical studies of type 3 chondrites-II. Thermoluminescence properties of sixteen type 3 ordinary chondrites and relationships with oxygen isotopes. Proc. Lunar Planet. Sci. Conf. 14th, J. Geophys. Res. 88, A791-795.

SEars D. W. G., Sparks M. II. AND RUBIN A. E. (1984) Chemical and physical studies of type 3 chondrites-III. Chondrules from the Dhajala II3.8 chondrite. Geochim. Cosmochim. Acta 48, 1189-1200,

SEARs D. W. G., MORSE A. D., HUTCHISON R., GUMMON R. K., ALEXANDER C. O., WRIGHT 1. P. AND PILIINGER C. T. (1988a) Alteration history of chondrules in the Semarkona ordinary chondrite (abstract). Lunar Planet. Sci. 19, $1051-1052$.

Siars D. W. G., Lu J., Gutmon R. K., MORSi A. D., Hutchison R., Alexander C. O., WRIGHT I. P. AND PILliNger C. T. (1988b) The thermoluminescence properties of chondrules from three low petrologic type ordinary chondrites (abstract). Meteoritics 23, 301.

SEARS D. W. G., DEHART J. M., ILASAN F. A AND LOFGREN G. E. (1989) Induced thermoluminescence and cathodoluminescence studies of meteorites. In Spectroscopic Characterization of Minerals and Their Surfaces (eds. I. M. Coyne, S. W. S. McKeever and D. I. Blake), pp. 190 222. American Chemical Socicty, Washington, D. C

SEARS D. W. G., HaSAN F. A., BATChelOR D. J. AND LU J. (1991) Chemical and physical studies of chondrites-XI: Metamorphism, pairing, and brecciation of ordinary chondrites. Proc. Lunar Planet. Sct. Conf. 21st, $493 \ldots 512$.

SIAARS D W G., LU JEE, BENOIT P. H DFILRT J $M$ AND IOFGrin G. E (1992) A compositional classification scheme for moteoritic chondrules. Nature 357, 207-210.

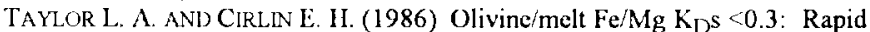
cooling of olivine-rich chondrules (absract). Lunar Planet. Sci. 17, 879-880.

TSUCHIYAMA A. NAGAHARA H. AND KUSHIRO I. (1980) Investigations on the experimentally produced chondrules: Chemical compositions of olivine and glass and formation of radial pyroxene chondrules. Proc. 5th Symp. Antarct. Meteorites Mem. Natl. Inst. Polar Res. 17, 83--94.

VAN SCHMUS W. R. AND WOOD J. A. (1967) A chemical-petrologic classification for the chondritic meteorites. Geochim. Cosmochim. Acta $31,747-765$

WALSH T. M. AND LIPSCHUTZ M. E. (1982) Chemical studies of L chondrites-1I. Shock-induced trace clement mobilization. Geochim. Cosmochim. Acta 46, 2491-2500

YANG J. AND EPSTEIN S. (1983) Interstellar organic matter in meteorites. Geochim. Cosmochim. Acta 47, 2199-2216.

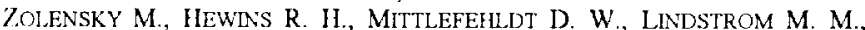
XIAO X. AND LIPSCHUTZ M. E. (1992) Mineralogy, petrology and geochemistry of carbonaceous chondritic clasts in the LEW 85300 polymict cucrite. Meteorifics $27,596-604$. 
